Louisiana State University

LSU Digital Commons

1987

\title{
Marital Relationships and Conflict Resolution Skills of Bulimics.
}

Dorothy Jo Van buren

Louisiana State University and Agricultural \& Mechanical College

Follow this and additional works at: https://digitalcommons.Isu.edu/gradschool_disstheses

\section{Recommended Citation}

Van buren, Dorothy Jo, "Marital Relationships and Conflict Resolution Skills of Bulimics." (1987). LSU Historical Dissertations and Theses. 4479.

https://digitalcommons.Isu.edu/gradschool_disstheses/4479

This Dissertation is brought to you for free and open access by the Graduate School at LSU Digital Commons. It has been accepted for inclusion in LSU Historical Dissertations and Theses by an authorized administrator of LSU Digital Commons. For more information, please contact gradetd@lsu.edu. 


\section{INFORMATION TO USERS}

The most advanced technology has been used to photograph and reproduce this manuscript from the microfilm master. UMI films the original text directly from the copy submitted. Thus, some dissertation copies are in typewriter face, while others may be from a computer printer.

In the unlikely event that the author did not send UMI a complete manuscript and there are missing pages, these will be noted. Also, if unauthorized copyrighted material had to be removed, a note will indicate the deletion.

Oversize materials (e.g., maps, drawings, charts) are reproduced by sectioning the original, begixning at the upper left-hand corner and continuing from left to right in equal sections with small overlaps. Each oversize page is available as one exposure on a standard $35 \mathrm{~mm}$ slide or as a $17^{\prime \prime} \times 23^{\prime \prime}$ black and white photographic print for an additional charge.

Photographs included in the original manuscript have been reproduced xerographically in this copy. $35 \mathrm{~mm}$ slides or $6^{\prime \prime} \times 9^{\prime \prime}$ black and white photographic prints are available for any photographs or illustrations appearing in this copy for an additional charge. Contact UMI directly to order.

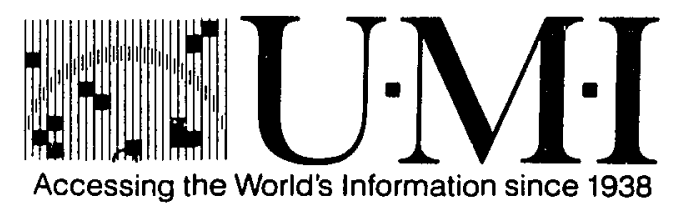


Order Number $\mathbf{8 8 1 1 4 4 0}$

Marital relationships and conflict resolution skills of bulimics

Van Buren, Dorothy Jo, Ph.D.

The Louisiana State University and Agricultural and Mechanical Col., 1987 


\section{PLEASE NOTE:}

In all cases this material has been filmed in the best possible way from the available copy. Problems encountered with this document have been identified here with a check mark

\section{Glossy photographs or pages}

2. Colored illustrations, paper or print

3. Photographs with dark background

4. Illustrations are poor copy

5. Pages with black marks, not original copy

6. Print shows through as there is text on both sides of page

7. Indistinct, broken or small print on several pages $\_$

8. Print exceeds margin requirements

9. Tightly bound copy with print lost in spine

10. Computer printout pages with indistinct print

11. Page(s) lacking when material received, and not available from school or author.

12. Page(s) seem to be missing in numbering only as text follows.

13. Two pages numbered . Text follows.

14. Curling and wrinkled pages

15. Dissertation contains pages with print at a slant, filmed as received

16. Other 
MARITAL RELATIONSHIPS AND CONFLICT RESOLUTION

SKILLS OF BULIMICS

\section{A Dissertation}
Submitted to the Graduate Faculty of the Louisiana State University and Agricultural and Mechanical College in partial fulfillment of the requirements for the degree of Doctor of Philosophy

in

The Department of Psychology

Dorothy Jo Van Buren

B.A., University of Kansas, 1980

M.A., Louisiana State University, 1983

December 1987 


\section{Acknowledgement}

The author would like to take this opportunity to thank those people whose help made this research possible. First, the author thanks the members of her comittee; Arthur Rlopelle, Ph.D., William F. Waters, Ph.D., Mary Lou Kelley, Ph.D., Drew Gouvler, Ph.D., and especlally Donald A. W1lliamson. Ph.D. who served as major professor and comittee chair. Many mental health facllities and professionals referred participants to this project. Special thanks go to Midi Williamson of the Center on Problem Eating, the staff and students of the Psychological Services Center at Louisiana State University, the staff of Talbot Outpatlent Center, Don Boone, and Kate Sitley, Ph.D. for referring participants to this study. The local media also played a role in the recruitment of subjects and the author would like to thank Smiley Anders of the Morning Advocate and Lynn Diaz of the State Times for running announcements of this project in thelr columns. In addition, the author would like to thank Mary Schlotterer, Kenny Bukta, Ashley Bourgeois and Chrls DeVille who served as raters for the videotaped communication segments used in this study. The author would also like to thank Pat Hives for her moral as well as practlcal support in getting equipment, handling messages, appointments, students, et cetera. Finally, a speclal thank you to Martin West whose love and understanding made the completion of this research project posstble. 


\section{Table of Contents}

Abstract vii

Introduction 1

Prevalence and Etiology of Bulimia 1

A Model of Bulimic Behavior and Related Problems 2

Interpersonal Functioning of Bulimics 3

Bulimics' Conflict Resolution Within the Family 5

Assessment of Married Couples' Conflict Resolution Skills 8

Direct observational techniques $\quad 8$

Self-report instruments 12

$\begin{array}{lr}\text { The Present Study } & 15\end{array}$

Method 16

$\begin{array}{ll}\text { Subjects } & 16\end{array}$

$\begin{array}{ll}\text { The Eating Questionnaire } & 17\end{array}$

$\begin{array}{ll}\text { Bulimia Test } & 18\end{array}$

$\begin{array}{ll}\text { Procedure } & 20\end{array}$

Dependent Variables $\quad 22$

Dyadic Adjustment Scale $\quad 22$

Conflict Inventory $\quad 22$

Relationship Belief Inventory $\quad 22$

Inventory of Marital Conflict 23

Communication Skills Test 24

$\begin{array}{lr}\text { Results } & 26\end{array}$

Relationship Satisfaction $\quad 26$

Beliefs About Relationships $\quad 27$

$\begin{array}{lr}\text { Conflict Resolution Styles } & 27\end{array}$

Discussion $\quad 29$ 
References $\quad 35$

Appendix A: Diagnostic Criteria 43

Appendix B: Structured Interview 44

Appendix C: Eating Questionnaire $\quad 47$

$\begin{array}{ll}\text { Appendix D: Bulimia Test } & 48\end{array}$

Appendix E: Consent Form 53

Appendix F: Dyadic Adjustment Scale $\quad 54$

Appendix G: Conflict Inventory 56

Appendix H: Relationship Belief Inventory 81

Appendix I: Handbook for the Communication Skills Test 83

Vita 98 
List of Tables

Table $1 \quad 19$

Table $2 \quad 21$

$\begin{array}{ll}\text { Table } 3 & 28\end{array}$

Table $4 \quad 30$ 


\section{List of Figures}

Figure 1 
Abstract

Bulimia is an eating disorder characterized by episodic binge eating and other related symptomatology. Previous research suggests that bulimics experience interpersonal problems particularly in the areas of conflict resolution and in their satisfaction with their roles within their families and marriages. The present study compared 12 bulimic couples to 14 maritally distressed couples and 15 normal control couples on measures of relationship satisfaction, conflict resolution styles, and beliefs about intimate relationships. In addition, couples' communication styles were analyzed based on their participation in an analogue conflict situation. Results of this study provide support for the contention that bulimics experience dissatisfaction with their interpersonal relationships and that they demonstrate deficient conflict resolution skills. Bulimics reported global relationship dissatisfaction with their marriages similar to the dissatisfaction felt by couples seeking marital therapy. However, bulimics' spouses were not as dissatisfied with their marriages as were the maritally distressed males. Bulimics were also similar to females in distressed marriages in their reported use of few problemsolving skills and withdrawal during conflict. Analyses of the analogue conflict discussions, however, did not confirm the presence of these self-reported communication deficiencies. In terms of beliefs about intimate relationships, bulimics and maritally distressed females subscribed to the dysfunctional belief that "Partners cannot change." These results suggest that clinicians working with bulimics need to be aware of the potential for marital problems in this population and to integrate some form of couples therapy or conflict resolution skills 
training in their treatment packages. The impact of such treatment components on the course of the bulimic's eating disorder and its treatment is a topic for future research. Although the results of this study lend support to previous clinical observations of bulimics, these data must be accepted with caution due to the small sample size and the selection bias inherent in the use of volunteer participants. 


\section{Marital Relationships and Conflict Resolution Skills of Bulimics}

In the third edition of the Diagnostic and Statistical Manual of Mental Disorders published in 1980, bulimia is described as an eating disorder characterized by the recurrent consumption of large quantities of food (binge eating). This binge eating is perceived by the individual to be abnormal and frequently accompanied by a depressed mood. The individual may express the fear that her eating is uncontrollable and she mar attempt to counteract perceived weight gain following a binge by inducing vomiting, using laxatives, or excessive fasting. The diagnostic criteria for bulimia are presented in Appendix A.

\section{Prevalence and Etiology of Bulimia}

The prevalence of bulimia in the general population is still unknown although it is thought to be a relatively common eating disorder among voung wom (Schlesier-Stropp, 1954). Several investigations have been conducted to assess for the prevalence of bulimia and they have yielded varving estimates suggesting that anywhere from $3.8 \%$ up to $16 \%$ to $17 \%$ of the wonen in the populations sampled were bulimic (Halmi, Falk \& Schwartz, 1981; Johnson, Stuckey, Lewis \& Schwartz, 1953; Moss, Jennings, McFarland \& Carter, 19S4; Pyle et al., 1983; and Strangler \& Printz, 1950). According to Mizes (1955) in his review of the bulimia literature this variability in prevalence estimates may be due to differences not onlv in the definitions of bulimia used, but also to the differences in the various populations sampled. There is increasing evidence that this eat ing disorder, which typically emerges in late adolescence, persists over time (Cullari \& Redmon, 1984). Due to the secrecy with which 
the bulimic engages in disordered eating behaviors and frequent absence of abvious medical or physical problems (Williamson, Davis \& Ruggiero, in press), it is not surprising that the average age of women presenting for treatment with bulimia tends to be older than the age at which anorexics first come into contact with health care professionals (Cullari \& Redmon, 1954: Foster, 1986; Pyle, Mitchell \& Eckert, 19S1). Despite its apparent prevalence and persistence little is known about the causes of this eating disorder.

Theories regarding the etiology of bulimia range from the almost exclusively biological (e.g., Pope, Hudson \& Jonas, 1983; Rau \& Green, 1975 \& 1954) to the almost exclusively psychosocial (e.g., Bruch, 197s; Sours, 1950). To date, no one theory of the origins of bulimia has received universal support. Although it is impossible at this time to say what causes bulimia, useful models have been constructed that allow for the srotematio exploration of the possible factors that maintain this eating disorder as well as its related problems (Stunkard, 1985). A Model of Bulimic Behavior and Related Problems

Williamson et al. (1955) provide a model of the antecedents and consequences of bulimic behavior that synthesizes various aspects of other proposed models (Rosen \& Leitenberg, 1952; Slade, 1952). This model sugerests that the binge eating of bulimia is a result of biological deprivation or hunger experienced by the individual. It is proposed in this model that the bulimic becomes very anxious after binging because of her fears of weight gain. She purges in response to this anxiety thus exporiencing a subsequent decrease in her feelings of anxiety. Unfortunately. purging also returns the bulimic to a state of biological 
deprivation, and in this way the binge-purge cycle is perpetuated. Another important aspect of Williamson et al.'s model of bulimia is that it also notes the potential for interpersonal and intrapersonal factors to impinge upon and in return be affected by the eating disorder (See Firure 1). Of particular interest is the commonly held belief that bulimics frequently experience interpersonal problems.

Interpersonal Functioning of Bulinics

Clinical observations of bulimic patients suggest that as a group ther are socially isolated, withdrawn, sensitive to rejection, have difficulty expressing emotions, and have poor conflict resolution skills (Johnson \& Pure, 1986; Yudkovitz, 1983). There appears to be a growing: body of research to substantiate these clinical observations. Williamson et al. (1995) found that bulimic women received higher scores on the Interpersonal-Sensitivity subscale of the SCL-90 than did obese and. normal control subjects. Pyle et 91 . (1951) surveyed 34 bulimics. Their subjects reported that they were experiencing interpersonal problems and that binges were frequently preceded by arguments. Schlundt, Jarrell \& Johnson (1983) provide further evidence for the role of interpersonal conflict in the perpetuation of binging and purging. They asked eight bulimic women to keep continuous records of their eating behavior. The investigators found that binge eating was frequently preceded by negative mood states. The authors speculate from clinical experience that such negative moods were produced by problematic interpersonal situations. Johnson and Berndt (1983) began an investigation of the social adjustment of bulimics which was followed up by Norman and Herzog in 19\$4. These two studies demonstrated that, based on responses to the Social Adjustment Scale, bulimic women experienced significantly more social maladjustment 


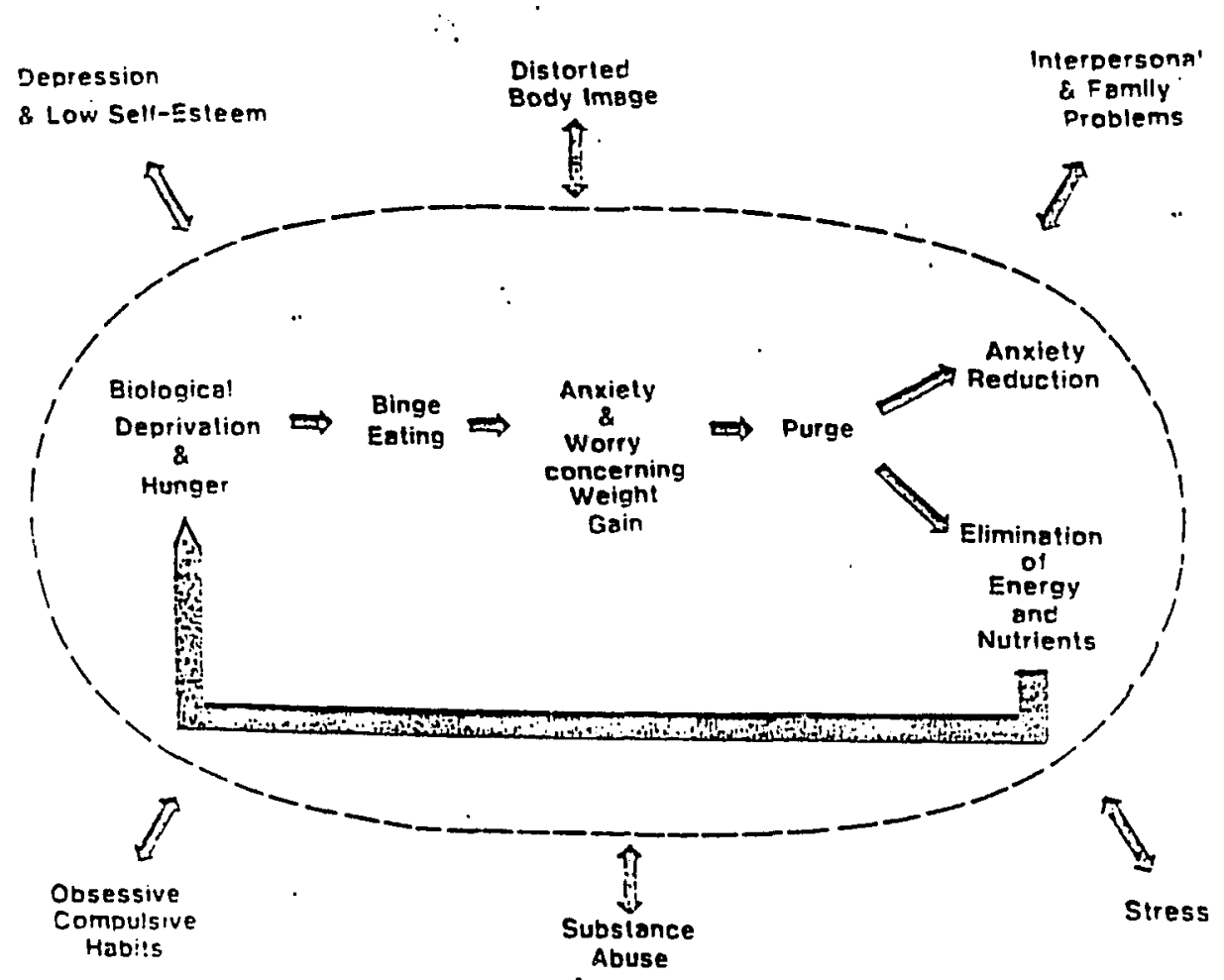

Figure 1: Williamson et al.'s (1985) model of bulimia 
than normal, alcoholic, and acutely schizophrenic women in terms of their roles within their families as wives and mothers and that this maladiustment persisted even after receiving treatment for their eating disorder. It has been suggested that one reason for bulimics' interpersonal problems is that they are unassertive and unable to handle conflict constructively (Loro, 1984). In a study of binge-eaters not necessarily diagnosed as bulimic, Hawkins and Clement (1984) found that such women reported being less socially competent in terms of assertiveness and dating skills than did women who were not binge-eaters. Despite growing evidence suggesting that bulimics have deficient interpersonal problem solving skills, few attempts have been made to more directly evaluate the types of responses bulimics utilize when engaged in interpersonal conflict.

\section{Bulimics. Conflict Resolution Within the Family}

One of the earliest studies involving the direct observation of the interactions between patients with eating disorders and their parents was conducted ky Minuchin, Rosman and Baker (1975). Minuchin et al. studied the functioning of anorectic as well as other "psychosomatic" families. They concluded that the families they studied exhibited four characteristic forms of interaction: 1)enmeshment; 2) overprotectiveness; 3 ) rigidity; and 4) inability to resolve conflict. Enmeshment describes the blurring of boundaries within a family so that j.ts members are overly sensitive to the moods and needs of other familv members making differentiation of individual needs and wants apart from the family difficult. Direct confrontation among family members in an enmeshed family is perceived to be very threatening to the 
homeostasis of the family system and is therefore unlikely to occur (Liebman, Sargent \& Silver, 1983). Overprotectiveness within a family is demonstrated by extreme intrusiveness and an inability to foster appropriate individual autonomy (Liebman et al., 1983). According to Minuchin et al. (1978), anorectic families that display enmeshment and overprotectiveness are further characterized by the rigidity with which they persist in these interactional styles based on the developmental stage of the family and their continued ineffectiveness. Since conflict is seen as so threatening and the flexibility required for problem negotiation is lacking in such families, successful conflict resolution is found not to occur. This finding that successful problem solving skills are lacking in families of anorexics has been further supported by more recent investigations (Garfinkel et al., 1983; Humphrey, Apple \& Kirschenbaum, 1986). However, recent research has called into question the wisdon of assuming that descriptions of anorectic families can be extrapolated to descriptions of families of normal weight bulimics (Sights \& Richards, 1984; Strober, Salkin, Burroughs \& Morrell, 1982) al though Schwartz, Barrett and Saba (1985) did report replicating Minuchin et al.'s (1978) observations in their intensive study of 30 bulimic families. However, Ordman and Kirschenbaum (1986) only partially found support for Minuchin et al.'s (1978) description of eating disordered families in their study of the families of 25 bulimics using self-report instruments. They administered the Family Environment Scale (Moos \& Moos, 1980) and the Family Adaptability and Cohesion Evaluation Scale (Olson, Bell \& Portner, 1978) to the participating bulimics but the bulimics' parents and/or other family members did not take part in this study. The bulimics scores on these 
instruments were compared to those of 36 control subjects. Ordman and Kirschenbaum (1986) found that the bulimics reported less familial cohesion and expressiveness than normals but they also reported more conflict in their families than did the control subjects. The low cohesion scores acheived by the bulimics somewhat contradicts findings of enmeshment and overprotectiveness in other eating disordered families. However, the bulimics' self-reported inability to express feelings openly ${ }^{*}$ ithin their families while experiencing a great deal of familial conflict is more in keeping with the ineffective conflict resolution skills noted in bulimic patients as well as in other eating disordered families. Therefore, there does exist some data to suggest that normal weight bulimics come from families in which conflict exists but is not openly or constructively dealt with. Schwartz et al. (1985) suggest that few family studies have been conducted with normal weight bulimics in part because of the higher average age of bulimics when compared to anorectic patients.

It is believed by many family therapists that marital interactions are influenced by and tend to replicate the interactional patterns of the dyad's families of origin. Therefore, due to bulimics' higher average age, research into their conflict resolution skills could more practically be done within their marital relationships. A number of established instruments for the assessment of couples' problem solving and conflict resolution skills exist as a result of work in the area of behavioral marital therapy. The presence of such instruments serves to further encourage research into the conflict resolution skills of this group of eating disordered individuals. 
Assessment of Married Couples: Conflict Resolution Skills

The study of conflict resolution and the problem solving skills of married couples has been an important part of the development of behavioral marital therapy. Three aspects of conflict resolution are generally assessed: The couples perceptions of their problem solving skills, their self-reported beliefs or cognitions regarding conflict and problem solving and their actual implementation of these skills. A variety of assessment instruments have been developed to allow for the examination of the various aspects of conflict resolution and problem solving.

Direct observational techniques. The Marital Interaction Coding System (MICS) was developed by Hops, Wills, Patterson and Weiss in 1971 as a means of objectively describing the interaction of couples as they discuss actual or analogue problem situations. The MICS is composed. of 30 behavimally defined scoring codes (Weiss \& Weider, 1952). Vincent, weiss and Birchler (1975) were able to differentiate distressed from nondistressed couples on the basis of the MICS. They found that dysfunctional couples enitted more negative problem solving behaviors and fewer positive problem solving behaviors than the functional married couples. However, the MICS is a complex instrument. It has been criticized due to the difficulty encountered in accurately calculating interobserver reliability (Jacobson, Elwood \& Dallas, 1981; Margolin \& Jacobson, 1981) and because of the prolonged time required for training observers to use it (Floyd \& Markman, 1984). Perhaps the difficulties inherent in the use of such direct observational techniques are one reason why thev have not, with one exception (Humphrey et al.; 1986), been used in the study of eating disordered indjviduals. Rather, when 
investigators have directly observed the interactions of individuals with eating disorders in problem solving situations they have made use of informal or unverified observation techniques. It was not until recently that a less complex coding system for the direct observation of couples" interactions was developed.

Flovg and Markman (1954) have developed the Communication Skills Test (CST). This observational method involves assigning a rating from five possible ratings ( $1=$ very negative, 2 =negative, 3 =neutral, 4 mositive, and $5=v e r y$ positive) to each complete statement made by each partner within the observed interaction. Each of the ratings reflects a cluster of descriptors of both verbal and nonverbal communication styles taken from previous research with couples. The CST not only allows one to assion an overall score to a couple's interaction that is reflective of their global commication style but it also allows one to track sequential interaction patterns more easily than with such complex mothods as the MICS. In addition, it provides for efficient calculation of interobserver reliabilities which Floyd and Markman (1954) reported ranging from .71 to .95 wth a mean of .82 on the CST. They found that the CST was senstive to changes in dating couples' communication styles as a result of theit perticipation in a communication skills training program and in comparison to control couples' communication. 'Therefore, the CST may provide a sound, easy to use method of quantifying the direct obspration of the problems solving interactions of eating disordered indridiuals with their spouses. With the CST one could determine in what wavs bulinies' problem solving styles actually differ not only from normal control couples but also from couples in malital distress in an efficient and reliable manner. 
The direct observational methods described above require that the couples being studied engage in some type of discussion which can be videotaped. In order to obtain this sample of behavior, couples have been asked to choose a problem relevant to their relationship to discuss or ther have been given topics to discuss chosen by the investigators thourht to approximate the type of conflict situations which might be encountered by cousles. Olson and Ryder (1970) developed a technique desiered to elicit problem solving and decision making behavior in courles caller the Inventory of Marital Conflict (IMC). This instrument consists of the description of 18 hypothetical problem situations. There are separate forms for husbands and wives. Some of the problem situations described on the two forms are identical and some of the descriptions diffe; somewhat between the husband and the wife's forms. Although the essential information about the problems are the same for both forms, the differences cause one partner to view one hypothetical partner as more responsjble for the problem than the other while his/her own husband or wifr reaches the opposite conclusion. Each partiner reads the IMC separately from his/her spouse and marks on the answer form who he or she thinks is at fault, the hypothetical wife or husband, and what she or he thinks would be the best of two possible solutions to the problem. In adrition, each partner rates each of the hypothetical problems as to their lelevance to his/her own relationship and other marital relationships. These latter ratings serve as manipulation checks to allow one to determine how relevant the later analogue conflict interactions may have been for the couple. After the couple has rated the IMC separately they are rejoined and asked to discuss each of the conflict situations. They are instructed to decide jointly through their 
discussion of each vignette who is most responsible for the problem and which of the two possible solutions is the most acceptable. Each partner is asked to record these decisions in the appropriate spaces on their indjvidual answer sheets. This interaction segment of the IMC yields two. sources of information about the couple under study. First, the actual problem solving style of the couple can be assessed by videotaping thejr discussion and using one of the observational scoring systems to code these behaviors. Second, the couple's recording of who is at fault and how the problem should be solved reveals which partner "wins" or which partner s point of view prevails. In this way one can assess for dominance in the relationship's problem solving interactions.

In their study of nearly 1000 couples Olson and Ryder (1970) found the IMC to be a valid and reliable tool for the assessment of couples. problem solvine and conflict resolution skills. It takes approximately one hour to complete if the entire inventory is used. However, it is constructed in such a way that half of the IMC can be administered cuttiner down significantly on the administration time. The IMC represents a standardized albeit analogue means of eliciting problem solving behavior from couples for direct observation.

Al though observational techniques have yielded a weal th of information regarding couples communication patterns they have their disadvantages. They are expensive and cumbersome to use. The videotape equiment and nanpower required to utilize these techniques is not always available. Furthermore, observational techniques do not access 
the belief systems or cognitions regarding conflict held by couples which are increasingly thought to play an integral role in couples' interactions (Margolin \& Jacobson, 1981). In contrast, self-report measures of couples' conflict resolution skills are seen as economical and as sometimes the only way to gain access to the thoughts and beliefs of spouses.

Self-report instruments. Margolin, Fernandez, Gorin and ortiz (1982) described the construction of a self-report measure of couples' conflict resolution techniques and their self-reported satisfaction with their patterns of resolving conflict. The Conflict Inventory (CI) consists of 26 items 20 of which fall into three major categories: Problem Solving, Withdrawal, and Aggression. All 26 items are repeated so that each partner can respond to them in five different ways; how of ten $s /$ he actually engages in the behavior, how of ten $s /$ he would like to engage in the behavior, how of ten does his/her partner actually engage in the behavior, how of ten would s/he like his/her partner to engage in the behavior, and how of ten does $s /$ he think his/her partner would like him/her to engage in the behavior. A six point rating scale (1=rarely to 6 =always) is used for each of the 26 items in all five of their variations. Comparing responses between spouses and within each partner's questionnaire can reveal not only the couple's rate of, but also their satisfaction with each other's and their own conflict resolving behaviors. In addition, the CI can provide a check of, the accuracy with which each partner perceives their conflictual interactions.

In a study of the discriminant and concurrent validity of the $\mathrm{CI}$, Margolin et al. (1982) administered the $\mathrm{CI}$ to 73 couples as part of an 
assessment package consisting of two other self-report questionnaires (the Dyadic Adjustment Scale -- DAS and the Conflict Tactics Scale -CTS). The DAS (Spanier, 1976) provides a measure of couple's overall satisfaction with their relationship. The CTS (Straus, 1979) is a 19 item self-report inventory. Each partner reports how of ten s/he used each of the 19 behaviors described within the CTS during the previous year when engaging in conflict with his/her partner. The items on the CTS fall into three different subscales: Reasoning, Verbal Aggression, and Violence.

Margolin et al. (1982) found that distressed couples differ significantly from nondistressed couples (as measured by the DAS) on all three subscales of the CI. Distressed couples engaged in more aggression, more withdrawal and fewer problem solving behaviors than their nondistressed counterparts. In addition, distressed couples are more dissatisfied with their own as well as their partners' behaviors on all subscales of the $\mathrm{CI}$ in comparison with nondistressed couples. Margolin et al. (1982) also correlated the three CI subscales with DAS scores. There were positive correlations between the DAS and the Problem Solving subscale and negative correlations between the DAS and the Aggression and Withdrawal subscales suggesting that the more dissatisfied a couple is the more likely they are to engage in aggression and to withdraw rather than use constructive problem solving. In terms of convergent validity, Margolin et al. (1982) found that the Reasoning subscale of the CTS was positively correlated with the CI's Problem Solving subscale while the CI Aggression subscale correlated with both the CTS' Verbal Aggression and Violence subscales. In addition, Withdrawal on the CI was correlated with the Verbal 
Aggression subscale of the CTS.

Despite the CI's preliminary demonstration of validity there are no data describing its reliability. However, it appears as though the CI may provide important information regarding spouse's perceptions of their own as well as their partner's conflict resolution skills. To date the $\mathrm{CI}$ has not been used with eating disordered individuals al though the instrument could yield information regarding the types of conflict resolution styles bulimics perceive themselves and their partners to use within their marriages in comparison to normal control and dysfunctional couples. Based on Loro's (1984) contention that bulimics tend to "give in and give up too quickly" in interpersonal problem situations one would think the CI would reveal that bulimics exhibit withdrawal in the face of conflict.

A different self-report instrument has been developed that assesses couples' beliefs and cognitions regarding conflict in their relationship as opposed to their self-reported conflict resolution behaviors. The Relationship Belief Inventory (RBI) was developed by Eidelson and Epstein (1982) as a means of easily assessing a wide range of potentially dysfunctional beliefs couples may hold about intimate relationships. The RBI consists of 40 items describing various beliefs about intimate relationships to which couples are to respond using a six point scale ranging from "I strongly believe that the statement is true" to "I strongly believe that the statement is false." The RBI is composed of five subscales consisting of eight items each. Each subscale represents a different maladaptive belief about relationships: Disagreement is destructive; Mindreading is expected; Partners cannot change; Sexual perfectionism; and The sexes are different. 
Eirlelson and Epstein (19S2) found with their sample of 200 couples (96 couples seeking marital therapy and 104 normal control couples) that a]1 of the RBI subscales were negatively correlated with the LockeWallace Marital Adjustment Scale (MAS; Locke \& Wallace, 1959) which provides a global measure of relationship satisfaction. Therefore, the RBI provides an easy to administer self-report measure of the types of bel iefs about relationships that may be dysfunctional, based on its correlation wth marital dissatisfaction. Bulimics evidence a number of irrational beliefs regarding weight and weight gain and it is possible that this tendency to entertain irrational beliefs may extend to some of their bejiefs about intimate relationships.

It has been suggested that individuals with eating disorders are ljkel\% to have difficulties in interpersonal relationships particular ly in the area of conflict resolution and problem solving. However, despite the piestence of a number of methods for the study of couples' conflict resolution skills, to date these instruments have not been used to examine empirically the intimate relationships of normal weight bulimics. Therefore: the following study was undertaken.

\section{The Present Study}

The present study was designed to examine the marital relationships ancl conflict resolution skills of individuals with bulimia. The study attempted to answer the following questions. How satisfied are bulimics with their marital relationships? What conflict resolution skills do bulimics use in intimate relationships? What unrealistic relationship beliefs do bulimics have? How do bulimics and their partners differ in 
these ways from normal and maritally distressed couples?

\section{Method}

Subjects

Fortyone couples participated in this study. Twelve of the couples had one partner who was seeking treatment for an eating disorder and were thus assigned to the Bulimic group, fourteen of the couples were seeking marital therany and were therefore assigned to the Distressed group, and fifteen of the couples were not involved in marital or eating disorders treatment and so were assigned to the Normal Control gloup. The type of therapr being sought was used as the sole criterion for group assignment. However, a structured interview and two self-report questionnaires were userl to ensure that individuals seeking treatment for an eating disorder warmong diagnosis of bulimia and to screen for the presence of potential eating disorders in the normal control and distressed groups.

Strotuirec interview. Only individuals seeking treatinent for an eating disorder who were assigned to the bulimic group participated in a structured interview (see Appendix B) to confirm the diagnosis of bulimia. The jnterview was conducted by the experimenter or an advanced graduate student in clinical psychology as part of a standard eating disorders evaluation and preceded the invitation for the bulimic and her partner to participate in the larger research project. Completion of the interview took one half hour to forty-five minutes. Although only individuals seeking treatment for an eating disorder underwent the structured interview, all subjects completed self-report instruments described below in order to screen for the presence of unreported eating disorders in the distressed and normal control groups and to 
further confirm the diagnosis of bulimia in the participants assigned to the bulinic group.

The Eating Questionnaire (Williamson, Kelley, Cavell, \& Prather, in press). The $E Q$ is a 16 item multiple choice questionnaire. It assesses for the presence of self-reported bulimic symptoms as described by DSM-III (APA, 1980). See Appendix C for a copy of the EQ. Unpublished research with the EQ has shown it to have good test-retest reliability and good concurrent validity. It has been used with various eating disordered as well as normal populations (D.A. Williamson, personal communication, July 1, 1987). The EQ was administered to all participants in this study. The highest possible score on the $\mathrm{EQ}$ is 80 and the lowest is 16 .

A series of chi square analyses were conducted on the individual questions from the $E Q$ in order to determine if the three groups differed in their self-report of specific symptoms of bulimia. Bulimics reported binge eating more of ten, $X^{2}(s, N=36)=15.32, p<.05$, as well as having more binge episodes per day, $X^{2}(8, N=36)=16.00, p<.04$, than normals or maritally distressed females. In addition, bulimics reported being more concerned about their binge eating, $\chi^{2}(8, N=36)=22.50, p<.004$, eating more rapidly during a binge, $X^{2}(8, N=36)=15.10, p<.02$, feeling more out-of-control during binges, $\chi^{2}(8, N=36)=29.40, p<.000$, and feeling more depressed following a binge, $X^{2}(8, N=36)=18.13, p<.02$, than normal control and maritally distressed females. These differences in specific responses to the EQ among the three groups was further supported by the results of comparisons of the total EQ scores for the three groups using an one-way analysis of variance. The bulimics' mean EQ score of 48.33 was found to be significantly higher than the scores of the normal control subjects $(M=32.42)$ and the distressed females $(M=35.58), F(2,40)=22.00, p<.0001$. Student Newman-Keuls 
post hoc analysis was used for this comparison. Table 1 provides the EQ means, standard deviations and $F$ values for the three groups.

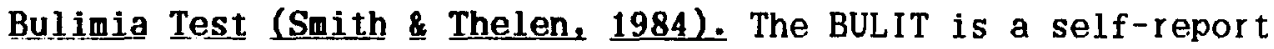
questionnaire consisting of 36 multiple-choice items. It was designed to be used as a screening instrument for symptoms of bulimia. The lowest possible score is zero and the highest is 160 . A score of 102 or greater is considered to be suggestive of bulimia. The BULIT's reliability and validity as a test of bulimic symptoms has been demonstrated in its use with samples of normal, bulimic, and anorexic college women (Smith \& Thelen, 1984). The BULIT was used in the present study to provide further confirmation of the diagnosis of bulimia for participants assigned to the bulimic group and to screen for bulimic symptomatology in the normal control and distressed subjects. See Appendix D for a copy of the BULIT.

An one-way analysis of variance was conducted using BULIT scores. Significant differences among the three groups of females were found, $F(2,40)=55.96, p<.0001$. Newman-Keuls post hoc test showed that bulimics' BULIT scores $(M=108.43)$ differed significantly from those of normal controls $(M=53.13)$ and distressed females $(M=59.14)$. See Table 1 for the means, standard deviations, and $F$ values for three groups on the BULIT. Therefore, the individuals assigned to the bulimia group at the outset of the study did report significantly more eating disorder symptoms than the individuals assigned to the other two groups.

Participants for this project were recruited from the married student population at Louisiana State University (LSU) in Baton Rouge, Louisiana, the Psychological Services Center at LSU, other area psychological services and eating disorders units, and media announcements regarding subject recruitment for this study. One out-of-state couple assigned to the bulimic 
Table 1: Comparison of the three groups of

females on the self-report eating disorder questionnaires, the Eating Questionnaire (EQ) and the Bulimia Test (BULIT).

\begin{tabular}{|c|c|c|c|c|}
\hline & \multicolumn{2}{|c|}{ EQ } & \multicolumn{2}{|c|}{ BULIT } \\
\hline & $M$ & $\mathrm{SD}$ & $M$ & SD \\
\hline \multicolumn{5}{|l|}{$\begin{array}{c}\text { Norma1s } \\
(\mathrm{N}=15)\end{array}$} \\
\hline \multicolumn{5}{|l|}{$\begin{array}{l}\text { Distressed } \\
(\mathrm{N}=14)\end{array}$} \\
\hline \multicolumn{5}{|l|}{$\begin{array}{c}\text { Bulimics } \\
(\mathrm{N}=14)\end{array}$} \\
\hline F value & \multicolumn{2}{|c|}{22.00} & \multicolumn{2}{|c|}{55.96} \\
\hline \multirow[t]{2}{*}{$d f$} & \multicolumn{2}{|c|}{2,40} & \multicolumn{2}{|c|}{2,40} \\
\hline & \multicolumn{2}{|c|}{$p<.0001$} & \multicolumn{2}{|c|}{$p<.0001$} \\
\hline
\end{tabular}

*different superscripts indicate statistically significant group differences among the means 
group because of the female's involvement in treatment for bulimia participated by mail and two bulimic females participated without their spouses. One of the distressed couples was cohabitating while all of the remaining couples were legally married. Two of the couples in the distressed group were black and the remaining couples were caucasian. The male partner was the bulimic in two of the couples assigned to the bulimic group, the remaining bulimics were females. In order to determine if the participants in this study differed in terms of demographics, four one-way analyses of variance were conducted; first comparing the males from each of the three groups with one another and then the females. Results of these analyses showed that the participants did not differ significantly in terms of age, years married, educational level, or income. Table 2 presents the means, standard deviations, and $F$ values for each of these variables for the males and females from each group.

\section{Procedure}

Couples who volunteered to participate in this project scheduled an initial assessment session with the experimenter. This initial appointment lasted one to one and one-half hours and involved reading and signing the consent form (see Appendix E), completing the self-report questionnaires described more fully below, participating in the videotaped task also described below, and the scheduling of a follow-up session lasting approximately one-half hour. During this session, the couple received feedback regarding the results of their participation in the study and the purposes of the research. Partners enrolled in undergraduate psychology classes at LSU received extra credit points for their participation.

Ten of the couples (two from the normal control group, six from the distressed group, and two from the bulimic group) did not participate in 
Table 2: Comparison of males and females from the three groups on demographic variables

\begin{tabular}{|c|c|c|c|c|c|c|c|c|c|c|}
\hline & & \multicolumn{2}{|c|}{ Normals } & \multicolumn{2}{|c|}{ D18tressed** } & \multicolumn{2}{|c|}{ 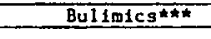 } & \multirow[b]{2}{*}{$F$} & \multirow[b]{2}{*}{ df } & \multirow[b]{2}{*}{ p) } \\
\hline & & $y$ & SD & M & SD & M & SD & & & \\
\hline \multirow{4}{*}{ Males } & Age & 37.67 & 9.97 & 35.07 & 8.81 & 38.50 & 9.61 & 0.56 & 2.38 & .05 \\
\hline & $\begin{array}{l}\text { Years } \\
\text { Married }\end{array}$ & 8.81 & 8.61 & 11.09 & 10.08 & 12.95 & 7.69 & 0.73 & 2,38 & .05 \\
\hline & $\begin{array}{l}\text { Years of } \\
\text { Education }\end{array}$ & 14.80 & 2.70 & 15.64 & 2.06 & 16.17 & 2.98 & 0.96 & 2.38 & .05 \\
\hline & $\begin{array}{l}\text { Estimated } \\
\text { Monthy } \\
\text { Income }\end{array}$ & 3251.33 & 1981.53 & 2676.07 & 999.61 & 3585.33 & 2520.71 & 0.77 & 2.38 & .05 \\
\hline \multirow{4}{*}{ Females } & Age & 35.20 & 7.65 & 32.50 & 9.61 & 35.50 & 7.13 & 0.58 & 2.40 & .05 \\
\hline & $\begin{array}{l}\text { Years } \\
\text { Yarried }\end{array}$ & 8.81 & 8.61 & 11.09 & 10.08 & 13.03 & 7.16 & 0.86 & 2,40 & .05 \\
\hline & $\begin{array}{l}\text { Years of } \\
\text { Education }\end{array}$ & 14.00 & 2.54 & 15.64 & 2.65 & 14.50 & 2.07 & 1.72 & 2.40 & .05 \\
\hline & $\begin{array}{l}\text { Estimaced } \\
\text { :tonthiy } \\
\text { Income }\end{array}$ & 3251.33 & 1981.53 & 2676.07 & 999.61 & 3400.64 & 2419.48 & 0.57 & 2,30 & .05 \\
\hline
\end{tabular}

$* \mathrm{~N}=15$ for both males and females $* * \mathrm{~N}=14$ for both males and females $* * * \mathrm{~N}=12$ for males
and $\mathrm{N}=14$ for females and $\mathrm{N}=14$ for females 
the videotaped portion of this study. Failure to complete this task was primarily due to the theft of the videotape equipment toward the end of the data collection phase of this study but also due to one couple's participation by mail. In addition, the two female bulimics who participated without their partners were unable to engage in the videotape task .

\section{Dependent Variables}

Dyadic Adjustment Scale (Spanier, 1976). The DAS is a self-report questionnaire consisting of 32 items which can be used to obtain a valid and reliable measure of global relationship satisfaction. Scores can range from zero to 151 on this instrument. One-hundred is the score used to differentiate satisfied from dissatisfied couples. Scores above 100 are indicative of relative relationship satisfaction while scores below 100 are indicative of relative dissatisfaction (see Appendix F). The DAS was administered to all participants in this study to assess for degree of relationship satisfaction.

Conflict Inventory (Margolin et al. 1982). As described in the introduction to this study, the $\mathrm{CI}$ is a self-report instrument of demonstrated validity designed to assess for individuals' conflict resolution styles. It results in three subscale scores: Problem Solving (seven items), Withdrawal (seven items), and Aggression (six items). Possible responses to each item range from $0=$ never to $6=$ almost always: Scoring results in an average score for each subscale (see Appendix G). The CI was administered to all subjects in this study in order to determine the self-reported conflict resolution styles of the participants.

Relationship Belief Inventory (Eidelson Epstein, 1982). The RBI, as described previously, is a 40 item valid and reliable self-report 
questionnaire designed to assess the degree to which individuals subscribe to five different dysfunctional beliefs about relationships. Each statement receives a rating of $0=" I$ strongly believe that the statement is false" to $5=$ "I strongly believe that the statement is true." Responses for each of the five subscales (Disagreement is destructive. Mind reading is expected, Partners cannot change, Sexual perfectionism, and The sexes are different) are totaled. The higher the resulting total the more that individual is thought to subscribe to that particular irrational belief (see Appendix $H$ ). The RBI was administered to all participants in this study as a measure of beliefs regarding conflict and intimate relationships in order to augment the other data collected on self-reported actual conflict resolution styles.

Inventory of Marital Conflict (01son Ryder, 1970). The IMC is an interactional task discussed $i$ the introduction of this study. Form $B$ of the IMC was used in this study. It was composed of nine vignettes about hypothetical marital problems. The IMC was administered first as a written questionnaire, which the partners completed independently, and then the partners were brought together to discuss their answers. The resulting 15 minute discussion provided the interactional component of the IMC. During the independent completion of the IMC each partner received somewhat different versions of six of the nine vignettes. Although the problem situations remained the same, some of the details varied from the husband's and the wife's versions. The partners used an answer sheet that had a summary of each vignette followed by two choices they were to make: Who, in their opinion, was most at fault for the problem and what, of two possible solutions, should be done to solve the problem. After completing 
this part of the IMC, the partners were brought together to discuss the vignettes. The more detailed versions of the vignettes were taken away from the partners and they were left with their answer sheets, which had the problem situation summaries and their answers recorded on them. The couples were instructed to discuss the problems and to come to two joint decisions regarding each vignette: Who's at fault and what should be the solution. The options for these decisions were the same ones given when the partners made these decisions independently. The analogue conflict arises from the fact that six of the vignettes given to the husband were phrased in such a way as to cast more blame on the hypothetical wife. The participating wife, on the other hand, was more likely to have seen the hypothetical husband as more at fault in the same six vignettes because of the way her vignettes were phrased. Therefore, coming from two different points of view, the couples were asked to come to a mutual understanding of the problem and to make joint decisions regarding ways to solve each problem. These joint decisions were then recorded by each partner on his or her own answer sheet .

No deception was involved in the use of the IMC. The participating couples were informed not only of the possibility of some of their vignettes differing from one another but also that their discussion would be videotaped. The videotape equipment was located behind a one-way mirror and the couple sat next to one another on a sofa. After 10 minutes had elapsed the couples were told they had five more minutes to complete their discussion. Therefore, a 15 minute analogue sample of conflict resolution skills was obtained from 31 of the 41 participating couples for analysis. Communication Skills Test (Flovd \&arkman, 1984). The CST, as discussed in the introduction, is ar observational scoring system developed 
as an easy to use, reliable means of analyzing couples communication skills. Four undergraduate research assistants were trained in the use of the CST. Training involved reading chapters one and two from A Couple's Guide to Communication by Gottman, Notarius, Gonso and Markman (1976) to familiarize the raters with the broader area of couples' communication skills, four one and one-half hour training sessions on the videotaped interactions of four couples who served as pilot subjects, and three, one hour booster training sessions after formal training had been completed.

Each statement made by each partner during the first 10 minutes of the videotaped interaction was assigned a rating of $1=$ very negative, $2=$ negative, 3 =neutral, 4=positive, or 5 =very positive. See Appendix 1 for a copy of the rating guidelines and the recording sheets used by the raters in this study. The ratings for each partner were totaled and averaged by the experimenter resulting in an average rating of communication style for each partner. The formula:

$$
\frac{A}{A+D} \times 100
$$

was used in the calculation of interrater reliabilities. For the purpose of calculating reliability, very negative (1) and negative (2) ratings were counted as agreements as were very positive (5) and positive (4) statement ratings. The raters were not aware of the group assignment of the couples they observed.

Interrater reliabilities during training ranged from $60 \%$ to $83 \%$ with an average interrater reliability of $73 \%$ at the end of the formal training period. Approximately one-third of the experimental tapes were used in an ongoing assessment of interrater reliability. These ongoing interrater reliability probes ranged from $60 \%$ to $87 \%$ with an average interrater. 
reliability of $78 \%$. The IMC as rated by the CST was used to gather direct observational data of the participating couples' conflict resolution skills.

\section{Results}

The data for this study were analyzed in two different ways. Initially, data from the first 12 couples for each group were analyzed using 3 (Group) $\times 2$ (Sex) between-subjects analyses of variance (ANOVAs) of the DAS and CST data and 3 (Group) $\times 2$ (Sex) between-subjects multivariate analyses of variance (MANOVAs) on the five subscales of the RBI and then on the three subscales of the $\mathrm{CI}$. Only the first 12 couples from each group were used in this set of analyses to ensure equal sample sizes so that the MANOVAs could be conducted. Next a series of 10 one-way ANOVAs were conducted comparing the cnree groups, using the data frand all 41 of the spouses on the dependent variables. Then all 43 of the bulimics', normal control females', and distressed females' data were analyzed using 10 one-way ANOVAs. In this way, data from the entire sample could be utilized. Throughout these analyses the Student Newman-Keuls post hoc tests were utilized.

\section{Relationship Satisfaction}

Relationship satisfaction as measured by the DAS showed a significant main effect for group, $F(2,66)=21.32, p<.0001$. Bulimic couples were found to be more distressed in their marriages than normal control couples ( $M^{\prime} s=90.96$ and 111.88 respectively) but not quite as dissatisfied as those couples seeking marital therapy $(M=81.00)$. Further analysis using the entire sample showed that bulimics and distressed females did not differ from one another although both groups of women differed from the control females. In addition, the spouses of bulimic, distressed and control females differed from one another. The spouses of the bulimics were more 
dissatisfied with their marriages than control spouses but not as dissatisfied as the male partners in the distressed group. See Table 3 for the means, standard deviations, and $F$ values for these comparisons. Beliefs About Relationships

A MANOVA of the couples beliefs about intimate relationships as indicated by their scores on each of the five subscales of the RBI did not show any significant main effects or interaction effects using Wilks' criterion, $F(10,124)=0.75, p>05$. However, a one-way ANOVA using data from the entire female sample showed significant differences between the three groups of women on the irrational relationship belief that Partners cannot change. According to the RBI, bulimics were similar to maritally distressed females in subscribing to this belief and both bulimics and distressed females differed from the normal control females' more realistic relationship belief in this area. However, the male spouses from the three groups did not differ on any of the five RBI subscales. See Table 3 for the means, standard deviations, and $F$ vaiues for these comparisons.

\section{Conflict Resolution Styles}

A MANOVA of the couples' conflict resolution styles was performed on the three subscales of the $\mathrm{CI}$. Wilks' criterion indicated significant main effects for group, $F(6,128)=3.03, p<.01$. Subsequent ANOVAs showed that bulimic and distressed couples reported using fewer problem solving skills when in conflict ( $M^{\prime} s^{\prime}=3.58$ and 3.59 respectively) than did control couples $(M=4.27), F(5,66)=7.04, p<.002$. In addition, bulimic and distressed couples reported withdrawing from conflict $\left(M^{\prime} s=2.66\right.$ and 2.70 respectively) more of ten than control couples $(M=1.94), F(5,66)=3.46$, $p<.01$. The couples did not differ in amount of aggression used in 
Table 3: Compartion of the males and females from the three groups on

the Dyadic Adjustment Scale (DAS) and the Relat lonship Bellef Inventory (RBI).

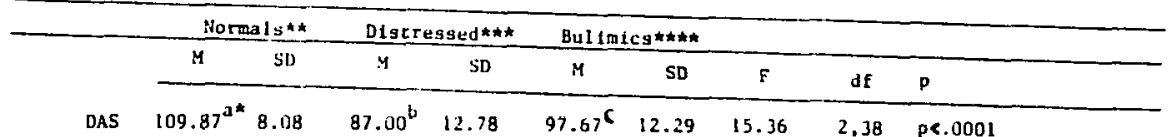

Maleu $\begin{array}{rrrrrrrrrr}\text { RBI } \\ \mathrm{D}\end{array}$

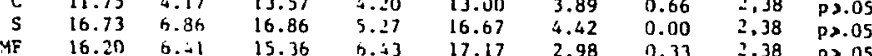

$\begin{array}{llllllllll}\text { DAS } & 118.47^{\mathrm{a}} & 11.90 & 76.71^{\mathrm{b}} & 23.55 & -86.4^{\mathrm{b}} & 21.81 & 18.24 & 2.40 & 0<.0001\end{array}$

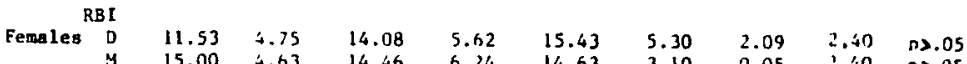

$\begin{array}{llllllllll}0 & 11.53 & 4.75 & 14.08 & 5.62 & 15.43 & 5.30 & 2.09 & 2.40 & 02.05 \\ 4 & 15.00 & 4.63 & 14.46 & 6.24 & 14.63 & 3.10 & 0.05 & 2.40 & 92.05 \\ c & 10.20^{d} & 3.41 & 15.69^{\mathrm{b}} & 7.36 & 13.43^{\mathrm{b}} & 6.26 & 3.16 & 2.40 & 95.05\end{array}$

$\begin{array}{llllllllll}\mathrm{c} & 10.20^{\mathrm{a}} & 3.41 & 15.69 & 7.36 & 13.43^{\mathrm{b}} & 6.26 & 3.16 & 2.40 & \mathrm{p}<.05 \\ \mathrm{~s} & 13.07 & 4.89 & 11.77 & 2.92 & 15.57 & 3.39 & 3.38 & 2.40 & \mathrm{p}>.05\end{array}$

*different superscripts indicate statistically significant group differences among the means

$* \star N=15$ for both males and femiles $* * * N=14$ for both males and females $* * \pi k N=12$ for males and $\mathrm{N}=14$ for females 
conflict as a function of group membership. When a one-way ANOVA was performed on all of the data for the female participants, it was found that bulimics and distressed females used problem solving less of ten than controls. In addition, bulimic and distressed females withdraw more of ten than control females. When analyzed separately using one-way ANOVAs the three groups of spouses did not differ significantly on any of the three CI subscales. See Table 4 for the means, standard deviations, and $F$ values for these comparisons.

An ANOVA conducted on CST scores for all of the participating couples showed no significant main effects in the ratings of the females' actual communication styles, nor for the spouses' communication. See Table 4 for a summary of the means, standard deviations, and $F$ values for these comparisons.

\section{Discussion}

The purpose of this study was to examine the marital relationships of bulimics and their partners in comparison to couples seeking marital therapy and normal control couples. The bulimics in this study resembled women seeking marital therapy in several ways. Not only did bulimics report a degree of global relationship dissatisfaction comparable to that of maritally distressed women but they also resembled them in terms of the use of few problem solving skills, withdrawal from conflict, and their endorsement of the irrational belief that their partners, as well as the quality of their relationships, cannot change. Eidelson and Epstein (1982) state that such a belief reflects an individual with "low efficacy expectations" who, therefore, is likely to "make fewer active attempts to constructively resolve conflicts." These results support 
Table 4: Cumparison of the males and females from

the three groups on the conflict resolution variables,

the Conflict Inventory (CI) and the Communication Skills Test (CST).

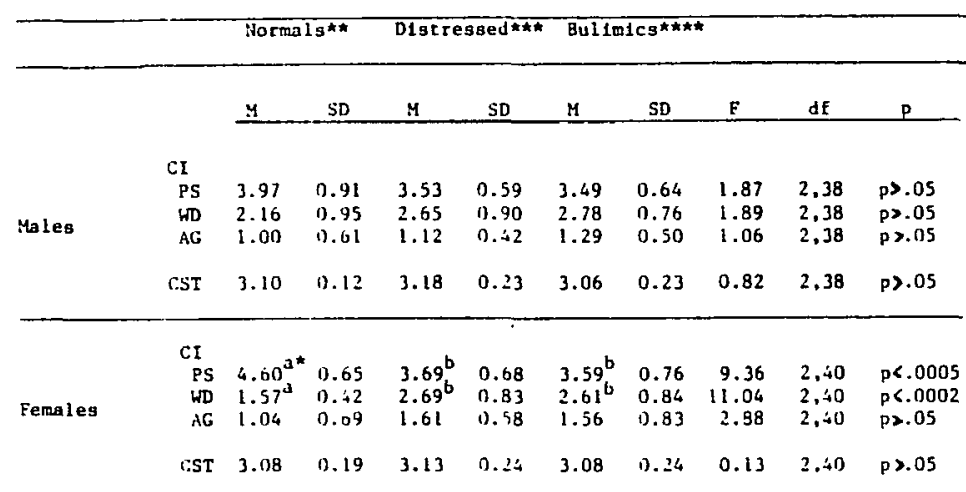

*different superscripts indicate statistically significant group

differences among the means

$\star \star N=15$ for males and Eemales $\star \star \star N N=14$ for males and females $\star \star \star \star N N=12$

for males and $\mathrm{N}=14$ for females 
prior observations that bulimics are deficient in problem solving skills (Loro \& Orleans, 1981), that they withdraw from conflict (Loro, 1984; Yudkovitz, 1983), and that they have disturbances in their interpersonal relationships (Johnson \& Berndt, 1983; Norman \& Herzog, 1984; Williamson et al.. 1985), particularly in their interactions with members of the opposite sex (Hawkins \& Clements, 1984; Johnson \& Berndt, 1983; Mizes, 1985; Yudkovitz, 1983). However, direct observation of the conflict resolution skills of bulimics and their partners did not show bulimics to be any less skilled than normal subjects. Perhaps had a different coding system been used, other aspects of bulimic couples' communication styles may have emerged in comparison to control and distressed couples. Floyd, O'Farrell and Goldberg (1987) compared the CST with the Marital Interaction Coding System (MICS, Hops et al., 1972) and found that negative, nonfacilitative behaviors as coded by the CST discriminated satisfied from dissatisfied couples while, conversely, positive, facilitative behaviors as coded by the MICS discriminated the satisfied from the dissatisfied couples. In light of the pattern of bulimics' responses on the $\mathrm{CI}$ indicating little use of active problem solving and their withdrawal from conflict, bulimics may be distinctive in their lack of facilitative communication skills rather than in their use of destructive communication skills and thus, based on Floyd et al.'s (1987) recent findings, the MICS would have been a more appropriate coding system for assessing for these differences.

The present study documented the presence of marital distress, poor conflict resolution skills, and irrational beliefs regarding relationships and the process of solving relationship problems in a bulimic population. Ilfeld (1982) has suggested that unsatisfactory 
marital relationships can be a source of stress for an individual and that his/her manner of dealing with these marital issues can in turn affect the level of stress actually experienced by the individual. It has been frequently noted that stress, particularly interpersonal stress, increases the likelihood of an individual engaging in binge eating (Mitchell \& Pyle, 1982; Morley, Levine \& Rowland, 1983; Polivy, Herman, Olmsted \& Jazwinski, 1984; Pyle et al., 1981; Schlundt et al., 1983; Wardle \& Beinart, 1981). For these reasons the results of the present study serve to further emphasize the need for clinicians to take into consideration that women seeking treatment for an eating disorder may be at risk for having the added stress of being involved in unsatisfying marital relationships. They are unlikely to be able to cope adequately with such stress because of their irrational relationship beliefs and poor conflict resolution skills. If not addressed, such added stressors may adversely affect the course and/or outcome of eating disorders treatment for bulimia. Therefore, the results of the present study suggest that training in interpersonal problem solving and conflict resolution skills might be added to the more standard behavioral and cognitive-behavioral treatments of bulimia (Fairburn, 1981; Rosen \& Leitenberg, 1982). Weiss, Katzman and Wolchik (1985) described a "psychoeducational" treatment program for bulimia that combines a focus on the modification of destructive eating and purging habits with training in assertion and anger expression. Preliminary treatment outcome research data are encouraging for the inclusion of such skills training components in a treatment program for bulimia that also emphasizes exposure to binge foods without purging (Agras, 1987). 
To date, however, no systematic study of the use of marital therapy as an adjunct to individual or group therapy for bulimia has been reported. The results of the present study would suggest that the utility of this type of treatment modality for married bulimics is worthy of further investigation.

Foster (1986) states that marital therapy for individuals seeking treatment for an eating disorder may be warranted when it appears as though changes within the relationship are accompanied by exacerbations in the eating disorder symptoms and if the identified patient reports marital distress. Foster (1986) sees resistence to couples therapy on the part of either spouse as a possible contraindication for couples therapy with eating disordered individuals. The results of the present study suggest that bulimics are experiencing a level of marital distress that is as intense as that felt by women in couples seeking marital therapy, the partners of the bulimics, although not as distressed as the maritally distressed spouses did report being more dissatisfied with their marital relationships than normal males. For these reasons research into the marital relationships of bulimics and the potential for couples therapy or the solicitation of partner support in the treatment of this disorder would seem warranted.

A major concern in interpreting the present results is the representativeness of the sample. Because participation in this project was voluntary, all the participants were self-selected. Therefore, the bulimics who volunteered for this project may have been those who happened to be maritally distressed and may not have represented married bulimics in general. Requiring relationship assessment as part of the 
standard assessment of bulimics at eating disorder treatment facilities would help in avoiding some of the selection bias inherent in the present study. In addition, research could explore whether bulimics' marital distress and irrational relationship beliefs abate and conflict resolution skills improve following treatment designed primarily to deal with the eating disorder symptoms or whether additional relationship therapy is necessary to impact on these problem areas in bulimics' interpersonal relationships. Primarily, the present study provides further support for Mizes' (1985) observation that our understanding of bulimia and its treatment will require continued exploration of the interpersonal as well as "personal deficits and difficulties" of individuals with this eating disorder. 


\section{References}

Agras, W.S. (1987). Eating disorders: Management of obesity, bulimia, and anorexia nervosa. New York: Pergamon Press.

American Psychiatric Assoclation. (1980). Diagnostic and statistical manual of mental disorders (3rd ed.). Washington, D.C: Author.

Bruch, H. (1978). The golden cage. Cambridge: Harvard University Press.

Cullari, S. \& Redmon, W.K. (1984). Questionnaire responses from selfidentified binge eaters and purgers. Psychological Reports, $\underline{54}$, 232-234 .

Eidelson, R.J. \& Epstein, N. (1982). Cognition and relationship maladjustment: Development of a measure of dysfunctional relationship beliefs. Journal of Consulting and Clinical Psychology, 50, 715-720.

Fairburn, C.G. (1981). A cognitive-behavioral approach to the treatment of bulimia. Psychological Medicine, 11, 707-711.

Floyd, F.J. \& Markman, H.J. (1984). An economical observational measure of couples' communication skill. Journal of Consulting and Clinical Psychology, 52, 97-103.

Floyd, F.J., O'Farrell, T.J. \& Goldberg, M. (1987). Comparison of marital observational measures: The Marital Interaction Coding System and the Communication Skills Test. Journal of Consulting and Clinical Psychology, 55, 423-429.

Foster, S.W. (1986). Marital treatment of eating disorders. In N.S. Jacobson \& A.S. Gurman (Eds.), Clinical handbook of warltal therapy (pp. 575-593). New York: Gullford Press.

Garfinkel, P.E., Garner, D.M., Rose, J., Darby, P.L., Brandes, J.S., 
O'Hanlon, J. \& Walsh, N. (1983). A comparison of characteristics in the families of patients with anorexia nervosa and normal controls. Psychological Medicine, 13, 821-828.

Gottman, J., Notarius, C., Gonso, J. \& Markman, H. (1976). A couple's guide to communication. Champaign, IL: Research Press.

Halmi, K.A., Falk, J.R. \& Schwartz, E. (1981). Binge-eating and vomiting: A survey of a college population. Psychological Medicine, 11, 697-708.

Hawkins, R.C. II \& Clement, P.F. (1984). Binge eating: Measurement problems and a conceptual model. In R.C. Hawkins II, W.J. Fremouw, \& P.F. Clement (Eds.), The binge-purge syndrome: Diagnosis, treatment, and research (pp. 229-253). New York: Springer Publishing Co.

Hops, H., Wills, T., Patterson, G.R. \& Weiss, R.L. (1971). The mar1tal interaction coding system (MICS). Unpublished manuscript. Department of Psychology, University of Oregon.

Humphrey, L.L., Apple, R.F. \& Kirschenbaum, D.S. (1986). Differentiating bulimic-anorexic from normal familles using Interpersonal and behavioral observational systems. Journal of Consulting and Clinical Psychology, 54, 190-195.

Ilfeld, F.W., Jr. (1982). Marital stressors, coping styles, and symptoms of depression. In L. Goldberger \& S. Breznitz (Eds.). Handbook of stress: Theoretical and clinlcal aspects (pp. 482495). New York: The Free Press.

Jacobson, N.S., Elwood, R.W. \& Dallas, M. (1981). Assessment of marital dysfunction. In D.H. Barlow (Ed.), Behavloral assessment of 
adult disorders (pp. 439-479). New York: Gullford Press.

Johnson, C. \& Berndt, D.J. (1983). Preliminary investigation of bulimia and life adjustment. American Journal of Psychiatry, 140, 774-777.

Johnson, C. \& Pure, D.L. (1986). Assessiment of bulimia: A multidimenstonal model. In K.D. Brownell \& J.P. Foreyt (Eds.), Handbook of eating disorders: Physiology, esychology, and treatment of obesity, anorexia, and bulimia (pp. 405-449). New York: Basic Books, Inc.

Johnson, C., Stuckey, M.K., Lewis, L.D. \& Schwartz, D.M. (1983). Bulimia: A descriptive study of 316 cases. International Journal of Eating Disorders, $2,3-16$.

Liebnan, R., Sargent, J. \& Silver, M. (1983). A family systens orientation to the treatment of Anorexia Nervosa. Journal of the American Acadeny of Child Psychiatry, 22, 128-133.

Locke, H.J. \& Wallace, K.M. (1959). Short marital adjustment and predictor tests: Their reliability and validity. Marriage and Family Living, 21, 251-255.

Loro, A.D., Jr. (1984). Binge-eating: A cognitive-behavioral treatment approach. In R.C. Hawkins II, W.J. Fremouw \& P.F. Clement (Eds.), The binge-purge syndrome: Diagnosis, treatment, and research (pp. 183-210). New York: Springer Publishing Co.

Loro, A.D., Jr. \& Orleans, C.S. (1981). Binge eating in obesity: Preliminary findings and guidelines for behavioral analysis and treatment. Addictive Behavors, $6,155-166$.

Margolin, G., Fernandez, V., Gorin, L. \& Ortiz, S. (1982, November). The Conflict Inventory: A measurement of how couples handle 
marital tension. Paper presented at 16 th Annual Meeting of the Assoctation for the Advancement of Behavior Therapy, Los Angeles. Marpolin, G. \& Jacobson, N.S. (1981). Assessment of marital dysfunctiion. In M. Hersen \& A.S. Bellack (Eds.), Behavioral assessment: A practical handbook (2cnd ed.) (pp. 389-426). New York: Pergamon Press.

Minuchin, S., Rosman, B.L. \& Baker, L. (1978). Psychosomatic families: Anorexia nervosa in context. Cambridge, MA: Harvard University Press. Mitchell, J.E. \& pyle, R.L. (1982). The bulinic syndrome in normal weight individuals: A review. International Journal of Eating Disorders, 1, 61-73.

Mizes, J.S. (1985). Bulimia: A review of its symptomatology and treatment. Advances in Behaviour Research and Therapy, 7 , $91-142$

Morley, J.E., Levine, A.S. \& Rowland, N.E. (1983). Minireview: Stressinduced eating. Life Sciences, $32,2169-2182$.

Moss, R.A., Jennings, G., McFarland, J.H. \& Carter, P. (1984). Binge eating, vomiting, and welght fear in a female high school population. The Journal of Family Practice, 18, 313-320.

Norman, D.K. \& Herzog, D.B. (1984). Persistent social maladjustment in bulimia: A 1-year follow-up. American Journal of Psychlatry, 141. $444-446$

Olson, D.H. \& Ryder, R.G. (1970). Inventory of Marital Conflicts (IMC): An experimental interaction procedure. Journal of Marriage and the Family, $32,443-448$.

Ordman, A.M. \& Kirschenbaum, D.S. (1986). Bulimia: Assessment of eating, psychological adjustment, and familial characteristics. 
International Journal of Eating Disorders, $\underline{5}, 865-878$.

Pollivy, J., Herman, C.P., Olmsted, M.P. \& Jazwinski, C. (1984).

Restraint and binge eating. In R.C. Hawkins II, W.J. Fremouw \&

P.F. Clement (Eds.), The binge-purge syndrome: Diagnosis,

treatment,and research (pp. 104-122). New York: Springer

Publi ishing Company.

Pope, H.G., Hudson, J.I. Jonas, J.M. (1983). Antidepressant treatment of bulimia: Preliminary experience and practical recommendations. Journal of Clinical Psychopharmocology, $\underline{3}, 274-281$.

Pyle, R.L., Mitchell, J.E. \& Eckert, E.D. (1981). Bullmia: A report of 34 cases. Journal of Clinical Psychiatry, 42, 60-64.

Pyle, R.L., Mitchell, J.E., Eckert, E.D., Halvorson, P.A., Neuman, P.A. \& Goff, G.M. (1983). The incidence of bulimia in college freshman students. International Journal of Eating Disorders, 2. $75-85$.

Rau, J.H. \& Green, R.S. (1975). Compulsive eating: A neuropsychologic approach to certain eating disorders. Comprehensive Psychiatry. 16, $223-231$.

Rau, J.H. \& Green, R.S. (1984). Neurological factors affecting binge eating: Body over mind. In R.C. Hawkins II, W.J. Fremouw \& P.F. Clement (Eds.). The binge-purge syndrome: Diagnosis, treatment, and research (pp. 123-143). New York: Springer Publishing Company.

Rosen, J.C. \& Leitenberg, H. (1982). Bulimia nervosa: Treatment w1th exposure and response prevention. Behavior Thrapy, 13, 117-124. Schlesier-Stropp, B. (1984). Bulimia: A review of the literature. 
Psychological Bulletin, 95, 247-257.

Schlundt, D.G., Jarrell, M.P. \& Johnson, W.G. (1983). A naturalistic

functional analysis of eating behavior in bulimia and obesity. Advances in Behaviour Research and Therapy, $7,149-162$.

Schwartz, R.C., Barrett, M.J. \& Saba, G. (1985). Family therapy for bulimia. In D.M. Garner \& P.E. Garfinkel (Eds.), Handbook of Psychotherapy for Anorexia Nervosa and Bulimia (pp. 280-307). New York: Guilford Press.

Sights, J.R. \& Richards, H.C. (1984). Parents of bulimic women. The International Journal of Eating Disorders, $3,3-13$.

Slade, P. (1982). Towards a functional analysis of anorexia nervosa and bulimia nervosa. British Journal of Clinical Psychology, 21, 167179.

Smith, M.C. \& Thelen, M.H. (1984). Development and validation of a test for bulimia. Journal of Consulting and Clinical Psychology, 52, $863-872$.

Sours, F. (1980). Starving to death in a sea of objects. New York: Jason Aronson.

Spanier, G.B. (1976). Measuring dyadic adjustment: New scales for assessing the quality of marriage and similar dyads. Journal of Marriage and the Family, $\underline{38}, 15-28$.

Strangler, R.S. \& Printz, A.M. (1980). DSM-III. Psychiatric diagnosis in a university population. American Journal of Psychiatry, $137,934-940$.

Straus, M.A. (1979). Measuring intrafamily conflict and violence: 
The conflict (CT) scales. Journal of Marriage and the Family, 41, 75-88.

Strober, M., Salkin, B., Burroughs, J. \& Mor rell, W. (1982). Validity of the bulimia-restricter distinction in anorexia nervosa: Parent personality characteristics and family psychiatric morbidity. The Journal of Nervous and Mental Disease, 170, 345-351. Stunkard, A.J. (1985). Research on bulimia comes of age. Advances in Behaviour Research and Therapy, 7, 199-203.

Vincent, J.P., Weiss, R.L. \& Birchler, G.R. (1975). Dyadic problem solving behavior as a function of marital distress and spousal vs. stranger interactions. Behavior Therapy, $\underline{6}, 475-487$. Wardle, J. \& Beinart, H. (1981). Binge eating: A theoretical review. British Journal of Clinical Psychology, 20, 97-109.

Heiss, L., Katzman, M. \& Wolchik, S. (1985). Treating bulimia: A psychoeducational approach. New York: Pergamon Press.

Weiss, R.L. \& Weider, G.G. (1982). Marital distress. In A.S. Bellack M. Hersen \& A.E. Kazdin (Eds.), International handbook of behavior modification and therapy (pp. 767-809). New York: Plenum Press. Williamson, D.A., Davis, C.J. \& Ruggiero, L. (in press). Eating disorders. In R.L. Morrison \& A.S. Bellack (Eds.). Medical factors and esychological disorders: A handbook for psychologists. New York: Plenum Press.

Williamson, D.A., Kelley, M.L., Cavell, T.A., Prather, R.C. (in press). Eating and eliminating disorders. In C.L. Frame \& J.L. Matson (Eds.), Handbook of assessment of childhood esychopathology: Applied issues in differential diagnosis and treatment evaluation. New York: Plenum Press. 
Williamson, D.A., Kelley, M.L., Davis, C.J., Ruggiero, L. \& Veitia, M.C. (1985). The psychophysiology of bulimia. Advances in Behaviour Research and Therapy, $7,163-172$.

Yudkovitz, E. (1983). Bulimia: Growing awareness of an eating disorder. Social Work, $28,472-478$. 
Appendix A: Diagnostic criteria for bulimia from the Diagnostic and Statistical Manual of Mental Disorders (3rd ed.).

1) Repeated binge eating with binge defined as the ingestion of a great deal of food in a relatively short period of time (two hours or less)

2) The belief that one's eating pattern is not normal and fear of of losing control over one's eating

3) Depression and negative self-thoughts following a binge

4) At least three of the following:

a. binging on easy to eat foods or high calorie junk foods

b. binging when alone or otherwise attempting to be secretive about binging

c. The binge eating stops when the individual self-induces vomiting, is interrupted, experiences stomach pain, or goes to sleep

d. a history of severe dieting and/or the use of purgative methods following binging ( $1 . \theta .$, self-induced vomiting, laxative abuse, and/or diuretic abuse)

e. fluctuations in weight of ten or more pounds as a result of binging and restricting

5) Anorexia nervosa or other physical health problems must be ruled out as causes of the bulimic symptoms 
Appendix B: Structured Interview

INTZRE SUHAAT

Eutinia Eingers and Butinia Binge/Durers

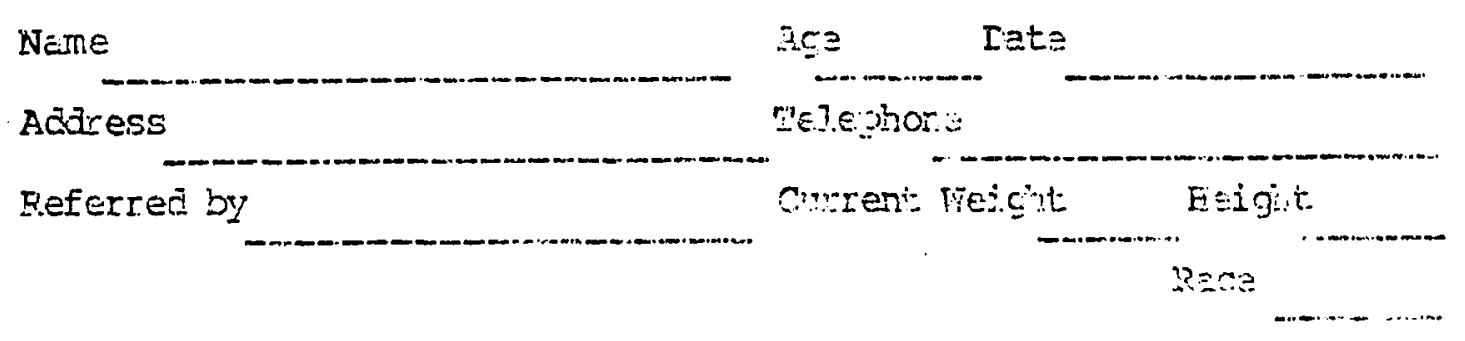

Eating/Veigit Histray

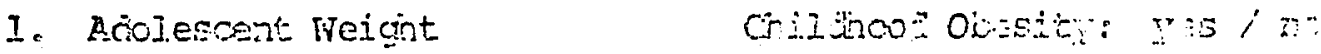

2. Any major weigit geins since acolescarce?

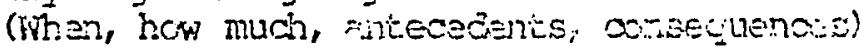

3. Any major veight losses since acolescencs?

(When, how much, antecedents, conseguencis:)

4. Do you feel you need to ?oss wicht now?

5. Have you ever been anorexic? If yes, describe situatirm,

6. Onset of binging? Onset of purging?

(When, contributing factora)

7. Course of binging or binge/pursing.

Decreases, increases in buimic beluavior. 
8. Current status of eating problem.

a. Binging: Frequency
Purging: Frequency of Day

b. Describe all covert and overt events that usually occur prior to, during, and after a binge-purge, or a binge.

Do you usually feel very hungry before binge eating begins?

c. Do you feel uncomfortable (anxious, troubled, etc.) after eating and before purging (if you purge or after eating if you do not purge)?

9. Who knows you are a bulimic/bincer or binge/purger? How do they react to your binging or binge/purging?

10. What have you done to stop purging and/or binging? How successful were you? (When, antecedents and consequences).

11. What factors/situations appear to increase or occasion binging and/or purging.

12. What factors/situations appear to decrease binging and/or purging?

13. Have you had any medical/dental problems? Check for dizziness, LBP, HBP, teeth erosion, thyroid, and diabetes.

14. What weight control techniques have you used? How often? How well did they work?

15. What regular exercise do you engage in? With whom?

16. Do you take laxatives or diuretics? If so, how often, how much

17. Nembers of household 
18. Are there any significant others who would participate in your treatment?

19. Are there any significant others who would interfere with your treatment? Describe any obstacles.

20. Other Comments: 
Appendix C: The Eating Questionnaire

Dincetiuns: In the spmce provided, Andicnte the tetten of the answer that best descrithes youn eatiug hehavios.

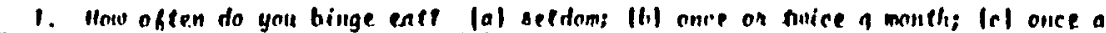

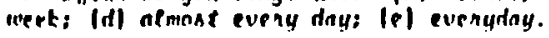

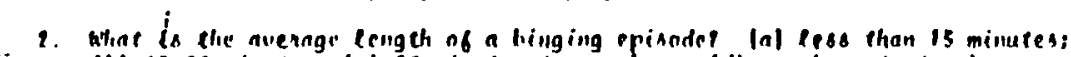

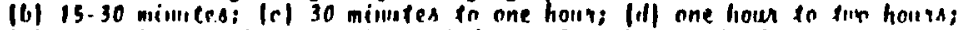

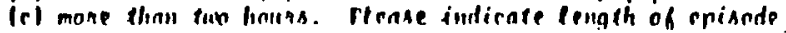

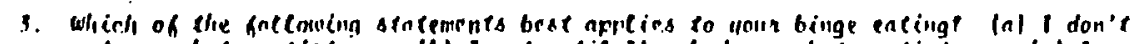

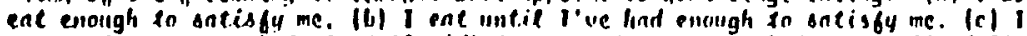
ent until my strmect ferle full. Inl I ent unfil my stomarh is mingully fult. lel I ent intil I can't ent anymnhr.

.- 1. Do you ever vomit affer a hingrf fal never; |hi abmet $25 \mid$ ef the time; $\mid$ el about

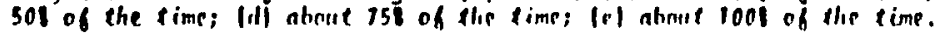

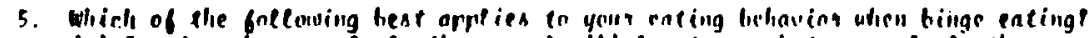

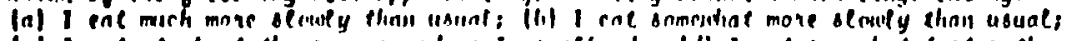

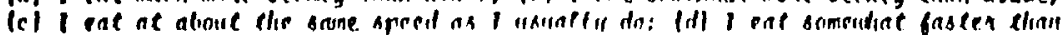

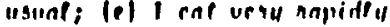

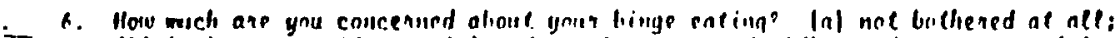

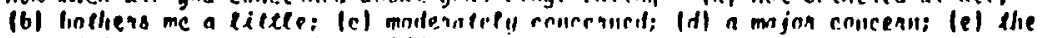
mose imprintant concent in my like.

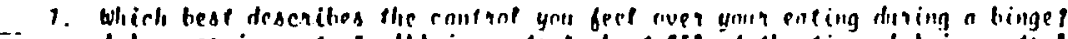

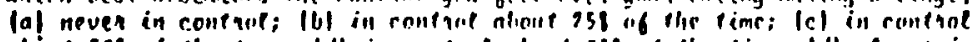

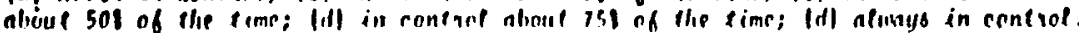

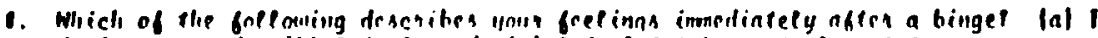

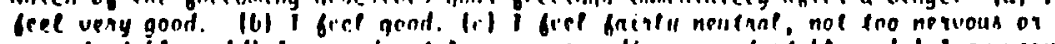

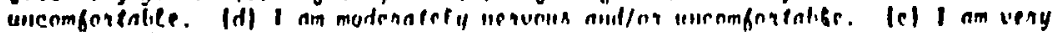
nenuous aint/on unermiontalep.

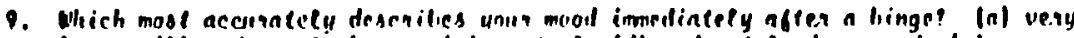

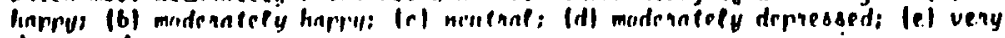
deriessed.

10. Which best describes the tupe of find you ent duaing a binnet In) hiqh ralonke jumk furd le.g., irer coramli thl high ratunle mealo le.g.. Pasinnals lal a

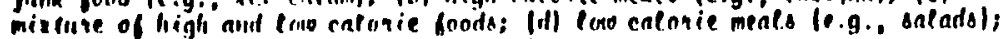

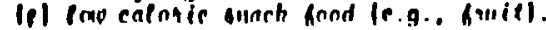

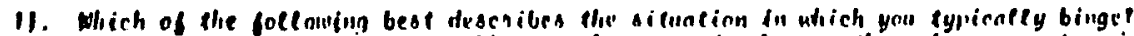

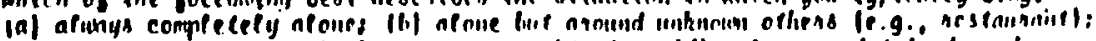

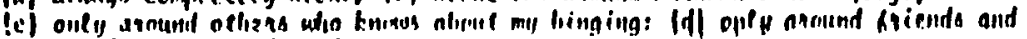
Irmily: lel te any sillention.

12. Which of the follenuing best describes any uright changed you have experiensed

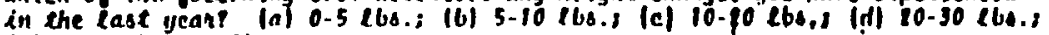
(el more thail 30 phs.

13. On a day that you birye, how many binge episodes typicafly becur during that dayp $|a|$ o; (b) 1; |c| 2; |di 3; |el tor mone. recase intigate frequescy

14. How often do you ise restrictive diets/fasts? $|a|$ never; $\mid$ b| I time per month; $|c|$ I times per multh; |d| I time per wesk; $|e|$ almost alunys.

15. Horo often do you use laxntives to ense ureighte (a) never; "ibl 1 -3 iimës per minith; (c) I time per wcek; (d) I time per day; lel mone than I time pet day. rease indicate hrequency

16. How obten do you use diunetics to ense uright? (a) never; $\mid$ b| $1-3$ times per month; (c) I cime pen weph; (d) I lime nen day; $|e|$ mone than 1 time per day. Please indicate onequenc.y 
PLEASENOTE:

Copyrighted materials in this document have not been filmed at the request of the author. They are available for consultation, however, in the author's university library.

These consist of pages:

APPENDIX D: The Bulimia Test by Smith and The len (1984) pp. 48-52.

APPENDIX F. The Dyadic Adjustment Scale

by Spanier (1976); pp. 54-55

APPENDIX G: The Conflict Inventory; pp. 56-80

APPENDIX_H: The Relationship Belief Inventory; pp. 81-82

\section{University Microfilms International}

300 N Zeeb Rd., Ann Arbor, Ml 48106 (313) 761-4700 
Appendix E: Consent Form

You nre bolng asised to pertlclpate in n reagntch project bolng

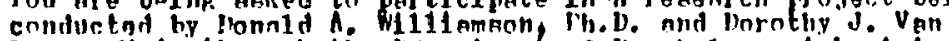
Buren. "I.A. throuph the lepartment of l'rychology at loul alnnn state Universlty. Flenre read tha followine, inenerintson of the promont oturiy carofuliy.

In this atudy your name will be lenpt atrletly constdantfol and all formn ynu f111 out oll1 unn codn numbere so that you mil not

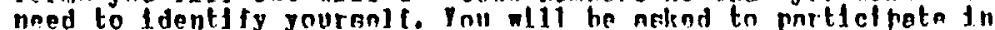
a structured interplon 18 you hare not al ready done no. In

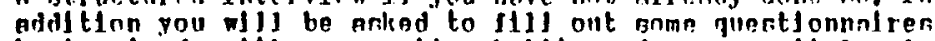
linving to io wli gnur eating liablte nod your mnittal relation-

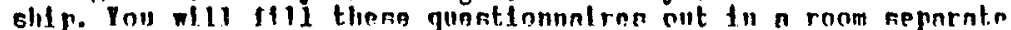
from your rpmurn. You enrl your annuse wly then be te-jnt ned

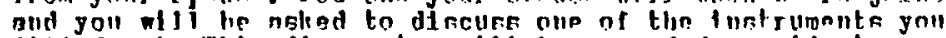

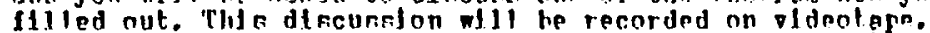
Pou may rcliedule an inrolntment mith the experimenten to raceive

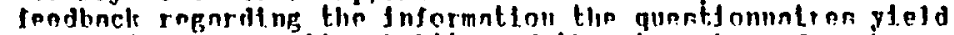

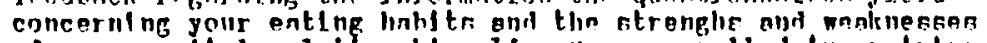

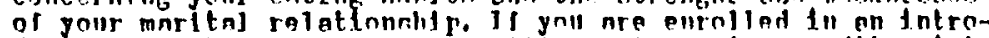

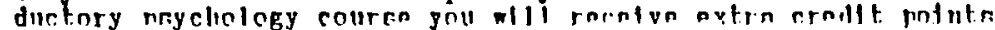
Ior your marticlention in thin rituily.

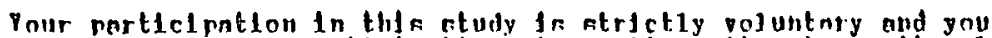

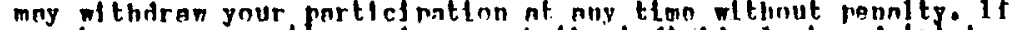

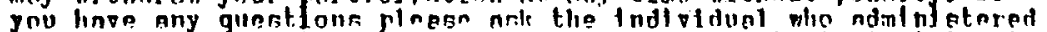

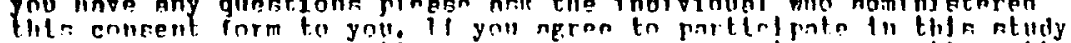

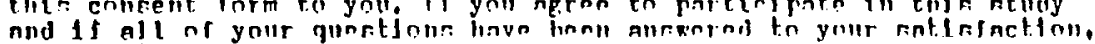
plenses alpe your nnma linlow.

I have raad the abnpe dasertintion of thie atudy and all my quastione have benn anronged to may entinsaction. i harahy voluntonr to

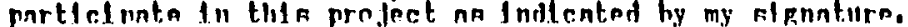

(Nama)

(hata)

\section{(withogs)}




\section{Appendix I:}

Handbook for the Communtcation Sk111s Test

Genera1 description:

The CST requires observers to make a 5-point rating of each statement emftted by subjects during their problem-solving interaction.

The observer attends only to the speaker and rates the speaker's statement: very negative - 1

negat ive -- 2

neutra1 -- 3

positive -4

very positive -- 5

Observers follow a two-step procedure in making CST ratings.

First: As the speaker talks, the observer scans the speaker's statement for the occurrence of individual positive, very positive, negative, and very negative communication/problem-solving behaviors (as defined within this booklet).

Second: When the speaker is $f$ inished, the observer then makes a judgement of the overall "positiveness" of the entire statement on the basis of the Individual behaviors emitted by the speaker during that statement using the scoring sheet.

These ratings reflect the degree of communication proficiency exhibited by the speaker.

Observers are given the following guidelines for judging CST scores:

When either positive, very positive, negative, or very negative behaviors occur within the context of otherwise neutral behavinis, the entire statement is rated in accordance with the type of positively or negatively valued behavior that occurred.

When both positive and very positive or both negative and very negat ive behaviors are combined in the same statement, the more extreme rating of very positive (5) or very negative (1) is given to the statement.

Statements containing only neutral behaviors are rated neutral (3).

Frequently behaviors with different positive and negative valences occur in the same statement. In this case observers are instructed to judge the relative contributions of the individual behaviors to the statement as a whole and to produce one CST rating that best reflects the overall level of communtcation skill exhibited in the statement. 
The Communication Ski1ls Test

$\underline{\text { Very }} \underline{\underline{P} \text { esitive }}=5$ points

A) Summarizing other or both:

Reveating back the content of what the partner has said and/or what both partners have sald up until that point before going on to present another point of view or solution.

Ex: "So what you're saying is ..." "What you've said so far is..."

"What $I$ understand is that..."

Your notes:

B) Checking out:

Similar to summarlzing but the goal is to make sure that the listener actually heard what was really meant by the speaker. To see if intent equals impact.

Ex: "I don't think you've been a spendthrift if that's what you felt I was saying..."

"I feel like you're making fun of me; Is that what you mean to do?"

Your notes: 
Very Pesitive continued $=5$ points

C) Opinion/feeling probe:

The speaker asks the listner how s/he feels or thinks about what was said or the topic at hand.

Ex: "What do you think bout that idea?"

"How do you feel about going out?"

"What's on your mind?"

Your notes:

D) Specific plan:

The speaker suggests a specific plan for solving the problem under discussion. To be specific, the plan is to include who is to do what under what circumstances (who, when, where).

Fx: "I think we shnuld divjde up the housework so that I do the dusting and vacuuming on Saturday mornings and you clean the bathrooms and mop on your day off."

"I could get the children bathed while you cook dinner on week nights and on the weekends

Your notes:

E) Specific feedback:

The speaker tells his/her partner what he/she thinks about what the partner has done or isaid and why.

Ex: "I like your idea because $1 t$ gives each of us some time to ourselves."

"I got angry when you criticized me in front of your mother." 


\section{Very posjtive continued $=5$ points}

H) Validation:

Similar to summarizing except that in addition to repeating back the content of the speaker's message the partner also repeats back the feelings the speaker has expressed. Validation deals more with the affect of the communication.

Ex: "You're feeling real bummed out about not getting that promotion."

"It's exciting for you to get to plan this year's family reunion."

"It makes you angry when I talk to other women at parties."

Your notes: 
Very positive continued $=5$ points

Your notes:

F) Back on beam:

The speaker says something to get the discussilon back on the original topic. This usually occurs in response to the partner having gotten off the topic but the speaker can also pull him/herself back on track if $\mathrm{s} /$ he has strayed from the discussion.

Ex: "Let's get back to discussing how to discipline

"I'm sorry, I think I got off track. What were we talking about?"

"We need to stay focused on the problem at hand before we start talking about that."

Your notes:

G) Metacommunication:

The speaker makes a statement that ties together

the preceding discussion.

Ex: "Not only have we discussed how little time we've been getting to spend with each other but we've actually come up with some cood solutions."

"Although the problem seemed to be that my mother interferes with us it has turned out that I'm really not assertive enough with her."

Your notes: 
Positive $=4$ points

A) Feeling statement:

The speaker expresses his/her own feelings in a direct and specific way. I feel bec ause

Ex: "I was angry when you came home. late last night." "I feel good when you compliment me."

"I get upset because you are yelling at me."

Your notes:

B) Agree or disagree with rationale provided:

The speaker agrees or disagrees with what his/her partner has said and gives a reason for his/her disagreement. or agreement.

Ex: "I agree that we need to take more time with the children because our work schedules have gotten busier."

"I don't think that is such a good plan since we already told our parents that we would alternate spending holidays with them."

Your notes:

C) Plan suggestion that is not specific:

The speaker makes a general statement about a possible course of action or problem solution but does not describe the who, were, when, and how of implementing the solution.

Ex: "We need to do more things together." "The problem is that we have too many debts so we need to spend less money." 
Positive continued $=4$ points

Your notes:

D) Compliment:

The speaker says something nice to his/her partner or makes some other positive comment to the partner regarding his/her appearance, behavior, and/or ideas.

Ex: "You sure have a way with words." "You did a nice job re-papering the kitchen." "That's a great idea!"

Your notes:

E) Clarification request:

The partner is asked to be more specific in his/her communication or is asked to clear up a possible mi scommunication.

Ex: "I'm not sure I understand what you're trylng to say."

"Would you explain what you mean?"

Your notes:

F) Accept responsibility

The speaker describes some way he/she is involved in the problem under discussion.

Ex: "I know that I have a tendency to interrupt you and that this makes it difficult to talk with 
Positive continued $=4$ points

"I probably haven't been doing as much housework as I should."

Your notes:

G) Empathy:

An expression of understanding that is less specific than that found in validation.

Ex: "I know how you must feel." "I can understand that you're upset." "That must be tough to take."

Your notes:

H) Summarizing self concisely or to clarify a point:

The speaker repeats what s/he was trying to say in a sentence or two without more elaboration. S/he may use this to clear up a possible misunderstanding.

Ex: "What I was trying to say is that I care about you." "As I said, I di sagree with that plan."

Your notes:

I) Humor

A partner says something light or funny during the discussion that does not appear to be sarcastic or a put down. 


\section{Pesitive continued $=4$ points}

Your notes:

J) Positf ve nonverval behaviors

Smiles, warm voice tone, and positive physical contact. Your notes: 
Neutral $=3$ noints

A. Problem talk, offering an opinton

Ex: "I guess we'd better get started."

"Which one are we on?"

"I think we should skip this one."

Your notes:

B. Asking a question

"What time is $1 t ? "$

"What do you mean?"

Your notes:

C. Agreement statement without providing rationale

Ex: "Sounds good."

"O.K."

"Whatever you say."

Your notes:

D. Information statement

Ex: "The children get home from school at $3 \mathrm{o}^{\prime}$ clock." "Your mother will not keep the children on Sundays." "We've been here an hour."

Your notes: 
Negative $=2$

A) Problem talk that is confusing or unclear

Your notes:

B) Opinions without rationale

Ex: "I think you should do the dishes."

"This is the way to handle it."

"It was definitely John's fauit."

Your notes:

C) Disagreement without rationale

Ex: "You're wrong about that."

"No."

"I don't like that idea."

Your notes:

D) Disruptive extraneous comments

Ex: "Damn, my back's acting up again."

Your notes: 
Negative continued $=2$

E) Negative nonverbal behaviors

Ex: frown, cold voice tone, rude gestures, etc.

Your notes: 
Very negative $=1$

A) Off- beam:

Occurs when discussion of one problem area drifts into discussion of other problem areas without any of the problems getting resolved.

Your notes:

B) Kitchen sinking:

Occurs when the discussion starts on one issue and, before there is time to explore that issue, one partner or the other drags in other gripes that may or may not be related.

Your notes:

C) Mind reading with negative affect:

Mind reading occurs whenever one person assumes what another person is either feeling or thinking without asking.

Ex: "I know you like romantic-type movies, so I made arrangements to go to see the new picture in town tonight -I'm sure you'li like $1 t^{\prime \prime}$

"The problem is that you feel that the house is a mess all the time - and that's just not true."

Your notes:

D) Putdown

Ex: "You're an 1diot."

"I can't get over how dense you are."

Your notes: 


\section{Very negative continued $=1$}

E) Summarizing self

Occurs when each person continues restating his or her won position. Each person is so sure he or she is right that they both think it's a waste of time to try to hear and understand the other person's viewpoint.

Your notes:

F) Blaming

Ex: "It's all your fault that it's taking so long." "If it weren't for you, I'd be a lot happier."

Your notes:

G) Character assassination

Occurs when one partner attributes bad or insulting characteristics or qualities to the other partner.

Fix: "You're an insensitive person."

"You're just like your mother, never satisfied." "You don't help around the house because you're lazy."

Your notes:

H) Yes, but...

Occurs when one partner's every attempt to make a suggestion or to state apoint of view has something wrong with it.

Ex: "I know, but...."

"But I do things that way because I love you."

Your notes: 
Date $\longrightarrow$ Rater Couple \#_ Tape \#

Inch Mark Begin _ End

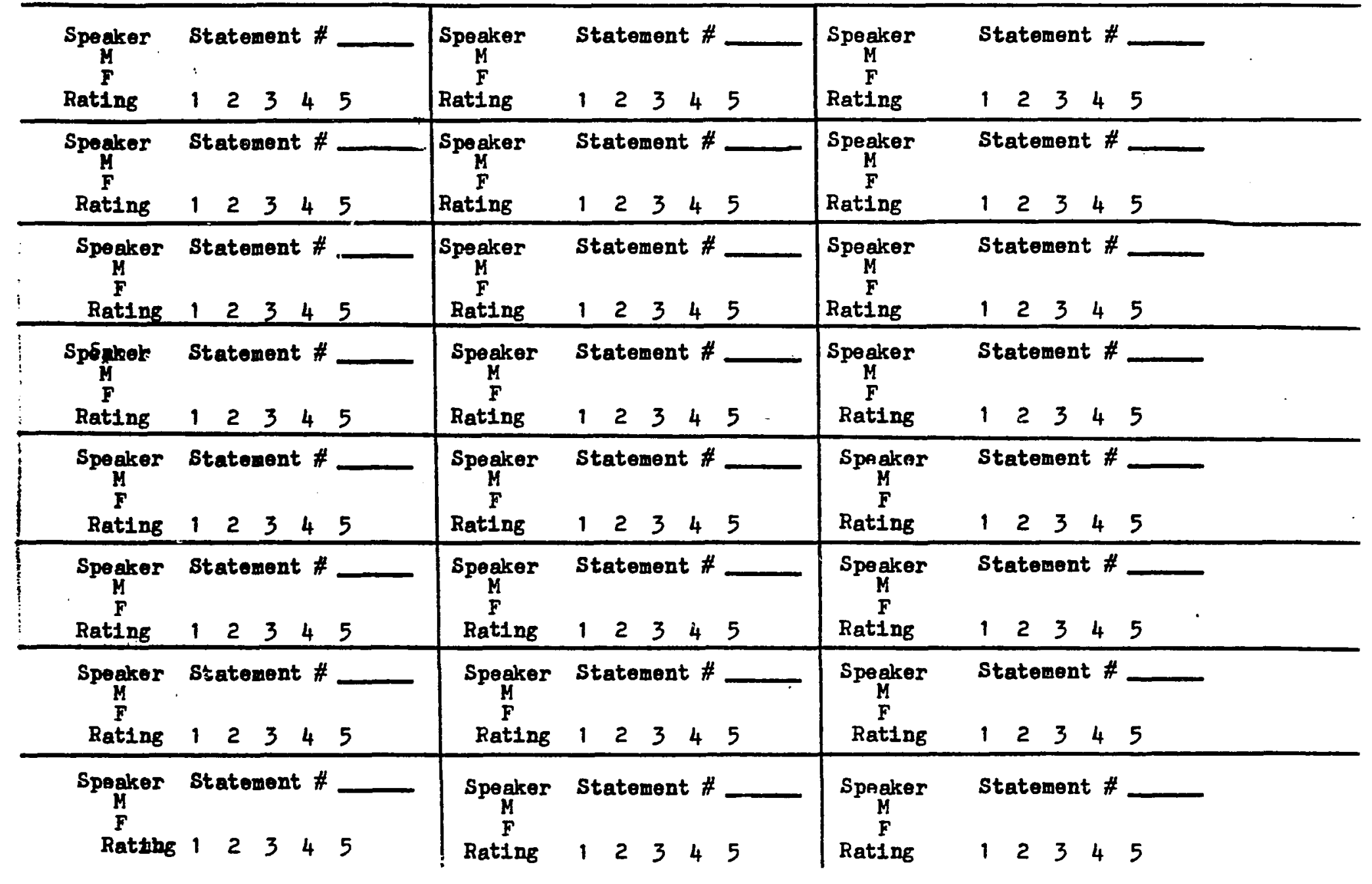


Dorothy Jo Van Buren

Apr 11 12, 1987

Personal Information

Date of Birth: January 20, 1958

Place of Blith: Johnson City, Tennossee

Marital Status: Marrled

Office Addiess

Talbot Outpatient Center

5414 Brittany Drlve

Sulte $C$

Baton Rouge, Louis lana 70809

(504)767-2977

llone Address

575 Burgin Avenue

Baton Rouge, Louls lana 70808

(504) 769-3579

\section{Education}

B.A. University of Kansas

Double Ma.lot: Psychology/Human Development

Degree amarded May 1980

M.A. L.oulslana Stato University

Major: Culnical Psychology (APA-approved program)

Minor: Behavloral Neurology

Degree awarded May 1983

Ph.d. Loulslana State University

MaJcr: Cllnical Psychology (APA-approved progran)

Minor: Behavloral Neurology

Degree anticlpated August 1987

\section{Uonors and Amards}

1980 Ph1 Beta Kappa

Graduetion $w !$ th distinction

Graduation with honors in psychology

1983 PhI Kappa PhI 
Clintcal Experdence

October 1985 present

November 1985 March 1986

Srptember 1984 -

- August 1985

August. 1983 -

May 1984

August $1982-$ May 1983
Talbet Qutpatient Center, Baton Rouge, Loulsiana. Conduct inf, Indlviduel and couples therapy 1 th an adult outpatlent population. Facllitator of the parent trainlng/support group. Served as therapist for groups designed to treat lndividuals ralsed in alcohollc or otherwlse dysfunctlonal homes.

Supervlsors: Donald A. W1lllamson,

Ph.D. and Johnny Matson. Ph.D.

Center on Problen Eoting (COPE). Baton Rouge General Medical Conter. Baton Rouge, Loulstana. Developed and saw to the Implementation of an outpatlent treatment progra for Individuals with eat ing disorders. Clinlcal Director: Carol. Alatalo Supervisor: Donald A. Hlllamson, Ph.D.

Clinical Hsychulagy lntern. University of Alabama in Birmingham (UAB) School of Medicine. Departaent of Psychlatry (APA-approved Internshlp).

Supervisor: Wlllian B. Beldleman, Ph.D.

Adult Clinic. Psychological Services Center (PSC), Loulsiana State Unlversity (LSU). Co-theraplst for group troatmont progran for bulinles. Also contucted general adult outpatient. assessment.s and treatment.

Supervlsor: Donald $\Lambda$. Wllliamson, Ph.D.

Pedietils Prycholory Serplce, Ear 1

K. Long Memor Lal Hospltal, LSIJ School of Medicine. Consultant to Inpetient and outpatlent pediatrlc service.

Performed intellectual and acaderic assessuents. Provided parent traintng and developed contingency management programs to Increase complianco with medical regimons.

Supervlsor: Mary Lou Relley, Ph.D. 
August 1981 -

Aurust 1982

Jnnuary 1981 -

May 1981

August 1990 .

Dercember 1980 Rosegrch Exper Lence

January $1987-$

present

August 1983 -

May 1991

August 1982 -

May 1983

August 1981

Hay 1982
Adult CLInLc, PSC, LSU. Provided assessment and trealment to edult outpatients. Co-Instructor for relationshjp enhancement class of fered through I.SU's Lelsure Servlces Program. Supervisor: Bernard I. Jensen, I'h.D.

Fadily Medlcine Gulnic. Farl K. Long Merorlal Hospltal, L,SU School of Medicine. Selved as consultant to fanlly practice physiclans. Piovided Inpatlent and outpatient assessent and treatment to adults and clildren. Supervlsor: Phlllip J. Brantley, Ph.b.

Comeunlty pgychology, LSU, Particlpated in organizational meetings of the Rlver Region Personal (irowth program. A t tended representational workshops and asslsted with programatlc research. Supervlsor: Ralph M. Dreger, Ph.II.

Part-tlne instructorshlo, LSU. Teaching a section of Chlld Psychology at the undergraduate level.

Supervisor: Johmny Matson. Ph.D.

Ieachlng Assistant, Adult Clinlc, PSC, LSU. Provided supetviston to first and second year clinjcal graduate sturents in assessment and rsychotherapy. Carrled out a variety of admintstrative tasks.

Supervisors: Nathanlel Gottfiled, Ph.D. and Bernard J. Jensen, Ph.D.

Researcb Assistant, LSU. Designed and implemented new and existing research projects in the areas of soclal skllls and marltal dysfunction. Supervisor: Bernard J. Jensen, Ph.D.

Teachlog Assistent, PSC, LSU. Carrled out adainistrative dutles.

Supervlsor: Nathanlel Gottfrled, Ph.D. 
May 1981 .-

Augus! 1991

Aupust 19:0 -

Ma! 1981

Aurust 1979 -

May IOS?

$1979-1984$
Restarch Assistant. Ear 1 K. Iong

Memor Inl Hospltal, ISU School of

Mediclne. Assisted In the collection

and summartzation of datn fot ongolug rosentch mojects

Supervisor: Phlllip J. Brantley, Ph.D.

Teaching Asststent. LSU. Wrote and PI adert exams. Suporvised unctergraduate Ifscarch assistant:i.

Sunctvisor: Yvome Haidaway-nsborne. Ph.D.

Rosenrch Assistant. Department of

Human Development. Universlty of

Kansas. Rated videotepes of chjldren's

play hehavior, colculated rollabllitles. traine! new raters, and developed bohnvioral definitjons to accombany conte categor tes.

Sunatvisor: C. Jan Carpenter, doctoral candidate

lectures fiven In undelgraduate and Ei aduate courses: Introduction to Rosonich Mothods wl th ihlidran, hbonoral Psychology, Theorles of Personal1ty. Psychology nf Adjustment. and Psychotherany l,ab.

Vresentullọns

Van Buren. [1.J. Iensen, B.J. Couples' evaluations of request makling: A sciclal valldily report. Poster presented at the 18th annesal conventlon of the Assoclatton for the Advancement uf Hrhavlol Therany (AABT), Phlladelplin, l'ennsyluanla, November, $198 \mathrm{~J}$.

Van Buren, D.J., Blenn, B., Mc.Anulty, D., Pallsl, S., \& Innsen, n... Couples' evalualions of a communicallon skilis tiaining progina. Posiar prisented ot the nnimal convention of the Southenstern Prscrhologlcal Associatlon (SF:PA), New Ol leans, Loulsiana, March 1984.

Van Buren, D.I., Brsutley, P.I., \& Martln, J.D. The relatlonshlp between knowlindge and motaholle control in diabntle patlents. Poster presented at the Hold Cungress in Behavior Therapy/ lith annual AMBT convention. Washlugton, D.C.. Necember 198.

Van Buren, D.J. A helavinral approach for preventing marltal discord. Paper presented in the symposium thlJel, "Prrvention of marlint d) ssatisfactlon: Improving Inllate relatlonships." nt the annual convention of SEPA. Atlanta, Gorgta. March 1983 
Varl Buren, D.J. How auch tine Is annugh: Refioctory perlods conslderral. Papel mesented In the syorosture titled, "Maybe they wll stow out of il: Tlae ns o esestrent varlable," at the annual

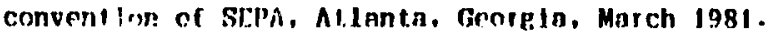

Ven Buren, I1.1., Houston, A., Holmes, D. The effects of gender specifirity on preschoulers' percoptlons of men and wanen's ahll!ty to partlcipale in val lous occupations. Paper presented In the sywosiue tstled. "An analysls of sicinlization fartors In the developant of young ehtidion's sex-typed behavior," at the annual convention of the Association for Behavloral Analysis, Dearborn. Michlgan. May 1980).

\section{Publicatiens}

Jensen, B.t. Van Buren, R.J. (1987). Cognitlug Hehnvior Theiapy: Concertual nind histoileal overview. The Southern Psychologist, $3,1-\bar{i}$.

Lemanek, K.l. Van Buran, D.J. (In press). Medlcal and health related disorders in schon and chlldien. In l.C. WItt. S.N. E.1) Lolt, F F. (jreshem (Eds.). Handbook of behaving therapy in aduratlon. New York: "lenum Press.

Mcknight, G.T., tock. T.B., KIng, A., Van Buren, D.J., \& Biantley, F.I. (I?g1). An evaluntion of cilnle functioning in five farl R. Loup Memolal llosplyal cutpatimit clinles. Jounal of the I.oujstana State Medlcal Society. 136, 29-30.

Prather, R., Unton, L., Willianson, D.. Denvis, C.J., Ruggloro, L., R Van furno. $n$. (In press). Bulimla, depression, and gimeral psychoraholopy. International Journal of Eating Wisorders.

\section{Professtonal Meaherships}

Ameilcan rsychologfeal Association

Assoclation for the Advancement of Behavior Therapy

Obesl: : Int Fating Dlsordnes Special Intesest fisul of AABT

Sinclote for Beliavioral Medloline.

Southastern Psycholegleal Assoclation 


\section{References}

Bernard J. Jensen. Ph.D.

Departrent of Psychology

Unlverslty of Cential Florsda

Orlando. Flar Ida 32816-0001

(305) $275-2216$

Mary Lou Kelley, Ph.D.

Department of Psychology

Loulslana State University

Baton Rouge, Louls lana 70803

(504) 388-8745

Johnny Matson. Ph.D.

Departaent of Psychology

Loulstang State University

Baton Rouge, Loulsiana 70803

(5ก4)388-8745

Donald A. M1lllamson, Ph.D.

Department of Psychology

Loulsiana State Unlversity

Baton Rouge, Loulsiana 70803

(504) 388-1494

(504) $388-8745$ 


\section{DOCTORAL EXAMINATION AND DISSERTATION REPORT}

Candidate: Dorothy Jo Van Buren

Major Field: Psychology

Title of Dissertation: Marital Relationships and Conflict Resolution Skills of Bulimics

Approved:
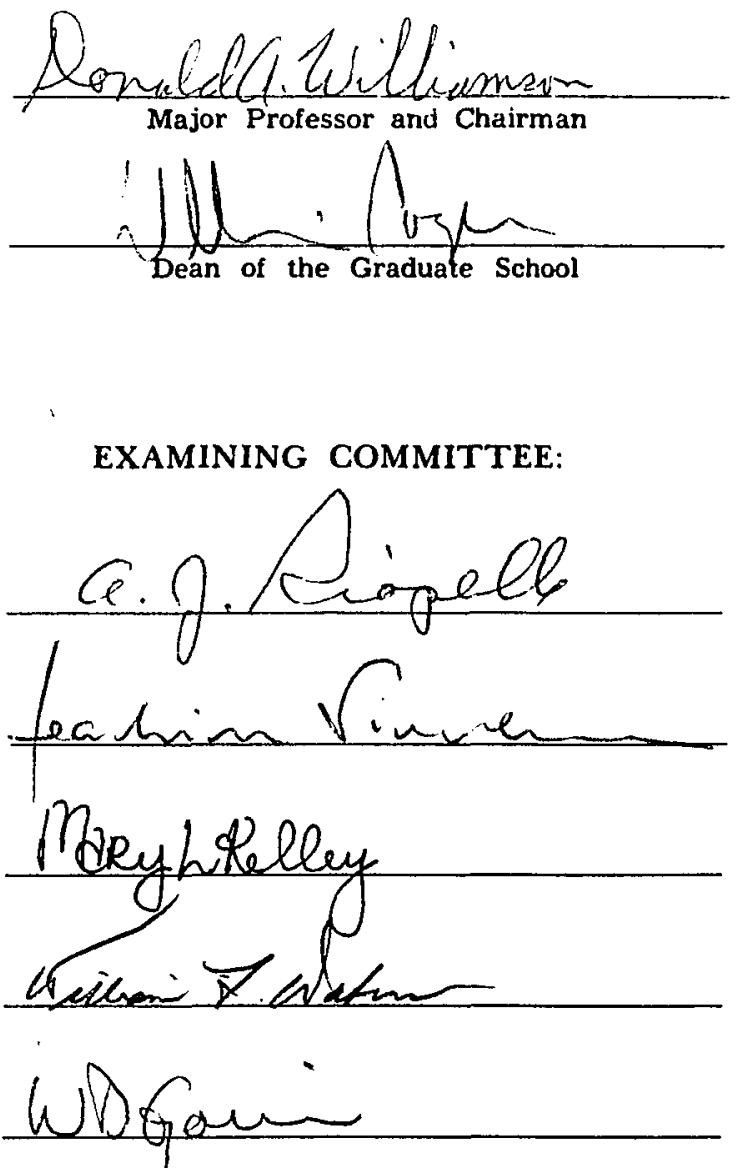

Date of Examination: 